\title{
New Era in the Treatment of Iron Deficiency Anaemia Using Trimaltol Iron and Other Lipophilic Iron Chelator Complexes: Historical Perspectives of Discovery and Future Applications
}

\author{
George J. Kontoghiorghes *(D), Annita Kolnagou, Theodora Demetriou, Marina Neocleous \\ and Christina N. Kontoghiorghe
}

check for

updates

Citation: Kontoghiorghes, G.J.;

Kolnagou, A.; Demetriou, T;

Neocleous, M.; Kontoghiorghe, C.N.

New Era in the Treatment of Iron

Deficiency Anaemia Using Trimaltol

Iron and Other Lipophilic Iron

Chelator Complexes: Historical

Perspectives of Discovery and Future

Applications. Int. J. Mol. Sci. 2021, 22,

5546. https://doi.org/10.3390/ijms

22115546

Academic Editor: Oleg V. Mikhailov

Received: 13 April 2021

Accepted: 18 May 2021

Published: 24 May 2021

Publisher's Note: MDPI stays neutral with regard to jurisdictional claims in published maps and institutional affiliations.

Copyright: (c) 2021 by the authors. Licensee MDPI, Basel, Switzerland. This article is an open access article distributed under the terms and conditions of the Creative Commons Attribution (CC BY) license (https:/ / creativecommons.org/licenses/by/ $4.0 /)$.
Postgraduate Research Institute of Science, Technology, Environment and Medicine, 3021 Limassol, Cyprus * Correspondence: kontoghiorghes.g.j@pri.ac.cy; Tel./Fax: +357-2627-2076

\begin{abstract}
The trimaltol iron complex (International Non-proprietary Name: ferric maltol) was originally designed, synthesised, and screened in vitro and in vivo in 1980-1981 by Kontoghiorghes G.J. following his discovery of the novel alpha-ketohydroxyheteroaromatic (KHP) class of iron chelators (1978-1981), which were intended for clinical use, including the treatment of iron deficiency anaemia (IDA). Iron deficiency anaemia is a global health problem affecting about one-third of the world's population. Many (and different) ferrous and ferric iron complex formulations are widely available and sold worldwide over the counter for the treatment of IDA. Almost all such complexes suffer from instability in the acidic environment of the stomach and competition from other dietary molecules or drugs. Natural and synthetic lipophilic KHP chelators, including maltol, have been shown in in vitro and in vivo studies to form stable iron complexes, to transfer iron across cell membranes, and to increase iron absorption in animals. Trimaltol iron, sold as Feraccru or Accrufer, was recently approved for clinical use in IDA patients in many countries, including the USA and in EU countries, and was shown to be effective and safe, with a better therapeutic index in comparison to other iron formulations. Similar properties of increased iron absorption were also shown by lipophilic iron complexes of 8-hydroxyquinoline, tropolone, 2-hydroxy-4-methoxypyridine-1-oxide, and related analogues. The interactions of the KHP iron complexes with natural chelators, drugs, metal ions, proteins, and other molecules appear to affect the pharmacological and metabolic effects of both iron and the KHP chelators. A new era in the treatment of IDA and other possible clinical applications, such as theranostic and anticancer formulations and metal radiotracers in diagnostic medicine, are envisaged from the introduction of maltol, KHP, and similar lipophilic chelators.
\end{abstract}

Keywords: maltol; ferric maltol; Feraccru; Accrufer; iron deficiency; iron deficiency anaemia; lipophilic chelators; alpha-ketohydroxyheteroaromatic chelators; pharmacology; clinical applications

\section{Introduction}

Normal biological, metabolic, physiological activities, and bodily functions are maintained in life due to the supply of essential nutrients, including transition metal ions, such as iron, copper, and zinc [1-9]. Healthy living is ensured following the acquisition of daily dietary requirements and maintaining a concentration of iron and other metal ions in the tissues. In contrast, iron and other metal metabolic imbalances are associated with serious clinical conditions [1-11]. In particular, one of these clinical conditions, namely iron deficiency anaemia (IDA), affects about one-third to a quarter of the world's population, with outcomes including increased child and maternal mortality, pregnancy complications, cardiac complications, fatigue, reduced physical and mental performance, paleness, koilonychia, etc. [12-15]. In most of these cases, the symptoms of iron deficiency are cured using iron supplements, which are widely available. 
Iron is found in all cells of the body. It is required for many essential bodily functions and physiological processes, including oxygen transport, storage, utilisation, and energy transduction [1-4,11].

Different mechanisms, pathways, and proteins are involved in the uptake, distribution, utilisation, recycling, and excretion of iron and other essential metal ions in humans, as well as other organisms. In this context, each cell requires and utilises different amounts of these metal ions for different biological functions [1-4,11]. The transfer of iron to all cells of the body is accomplished by transferrin present in blood and is mediated through transferrin receptors present on the cell membrane [11,16-18]. Intracellular iron storage is accomplished by ferritin and haemosiderin. One molecule of ferritin can store up to 4500 molecules of iron and haemosiderin is a cluster of ferritin molecules with a broken protein shell, which mainly predominates over ferritin in iron loaded conditions [11,19-22].

In relation to the human body, about 4.5-5.0 $\mathrm{g}$ of iron is estimated to be present and distributed in blood and different organs of a 70-75 kg average adult man. Most of the iron is in the ferrous state in a complex form with a protoporphyrin ring (haem), in the protein haemoglobin (2.3-2.6 g) found in red blood cells (RBC), and myoglobin (0.32-0.40 g) found in the muscle. The remaining iron is distributed in the body mainly in the form of polynuclear ferric oxyhydroxide phosphate complexes in the iron storage proteins ferritin ( $0.7 \mathrm{~g})$ and haemosiderin $(0.3 \mathrm{~g})$ found mainly in the liver, spleen, muscle, and bone marrow. Iron is also found in other proteins, such as mitochondrial cytochromes (17 $\mathrm{mg})$, catalase (5 mg), transferrin (4 mg), and non-haem iron containing enzymes (0.1 g) [11].

Under normal physiological conditions, iron is mainly found in the ferrous $\left(\mathrm{Fe}^{2+}\right)$ or ferric $\left(\mathrm{Fe}^{3+}\right)$ state forms, always bound to different ligands containing oxygen, nitrogen, and sulphur [11]. At physiological $\mathrm{pH}$, ferrous iron in aqueous solutions is oxidised to ferric iron, which is only found in trace detectable levels, since it mostly precipitates by forming insoluble polymeric ferric oxyhydroxide complexes with a high stability constant $(\log \mathrm{K}=38)[11]$. The solubility of iron and other metal ions increase at acidic $\mathrm{pH}$ including the acidic environment of the stomach.

Many molecules, including food components and drugs, contain metal binding ligands, which can form complexes with iron. The complexes being formed can affect the solubility, interactions, and transfer properties of iron across cells in the gastrointestinal tract and in other parts of the body [11,23].

Different pharmacological, toxicological, and therapeutic characteristics of iron complexes are observed in vivo, which depend on the size, solubility, lipophilicity, and stability of the complex, as well as other physicochemical parameters $[11,24,25]$. Furthermore, the characteristics of the iron complexes are also influenced by competing endogenous low molecular weight chelating molecules and iron chelating proteins, such as transferrin and lactoferrin $[26,27]$. Following these interactions and exchanges the chelator involved in the iron complex is, in most cases, dissociated, and the iron molecule enters the iron metabolic pathways. The chelator dissociated from the iron complex has different metabolic, toxicological, and pharmacological properties in comparison to the chelator iron complex [28].

Iron and other metal metabolic imbalances are associated with serious medical conditions such as IDA, which affect billions of the people worldwide [12-15]. Iron deficiency anaemia could be caused by many genetic, nutritional, metabolic, and other factors, as well as diseases [12-15,29-33]. Iron supplementation is used in food products, such as cereals or prescribed by physicians in most cases for the treatment of IDA, including many and different oral ferrous and ferric iron complex formulations, which are widely available and sold worldwide at pharmacies [13].

There are many safety concerns arising from the uncontrollable use of iron supplements, mainly because of the potential toxicity implications arising from the free radical catalytic and carcinogenic properties of iron. In general, only a small portion of orally administered iron is absorbed, and most of it is excreted in the faeces. The presence of excess iron is toxic to the cells of the gastrointestinal tract [34]. Furthermore, some iron 
complexes, including those with nitrites and haem components found in processed and red meat, respectively, are suspected to be major causes of colorectal and other cancers [35].

Despite the wide availability of oral ferrous and ferric iron formulations, and of intravenous iron formulations in the treatment of IDA, there is scope for further improvement, especially in relation to safer and more effective targeting, with the ultimate aim to control increased iron absorption and delivery to haematopoietic and other tissues. In this context, trimaltol iron (International Non-proprietary Name: ferric maltol, Feraccru or Accrufer), and other lipophilic chelator iron complexes appear to offer improved therapeutic advantages in the treatment of IDA conditions in comparison to traditional oral iron formulations, which are generally linked to gastrointestinal toxic side effects, and in some cases, complications associated with exacerbation of other pre-existing underline diseases $[11,23,34,36]$.

\section{Iron Absorption and Distribution Pathways}

Under normal conditions, the absorption of iron in the gastrointestinal tract and the distribution pathways to the haematopoietic and other tissues are regulated and controlled by a number of proteins and transcription factors, as well as other genetic, environmental, nutritional, and other factors $[1-4,11,23,36]$.

\subsection{Iron Absorption in Humans}

Iron absorption in humans under normal conditions is thought to be controlled by a number of regulatory proteins of iron metabolism, which in conjunction with other regulatory pathways of iron utilization and excretion leads to body iron balance.

In general, iron balance in the human body is maintained when the amount of iron absorbed is equivalent to the amount of iron lost through excretion and other routes [23]. This dynamic balance is usually controlled and operated within limitations provided by the regulatory pathways and are mostly influenced by dietary iron and the haematopoietic activity [1-4]. Minor changes in iron balance can usually be restored at a different rate, depending on the level of change in the iron stores. For example, in blood donors or long distance runners iron loss is gradually restored from increased dietary iron absorption $[37,38]$. However, imminent blood transfusion is required following excessive bleeding, for example, after motor accidents or surgery, where there is substantial loss of blood and iron, as well as limited capacity in rapidly restoring these losses. Similarly, iron balance is restored when, for example, excess iron is gradually lost from patients who receive iron supplements long-term, or a small number of transfusions [23].

In contrast, iron imbalance could also be caused and maintained in conditions where the rate of iron absorption may be greater than the rate of iron loss, as shown in African siderosis (Bantu siderosis), or where the rate of iron loss may be greater than iron absorption, as shown in vegetarian populations with IDA or in malnutrition, which is caused by insufficient intake of dietary iron [23]. In addition to genetic and regulatory factors, many nutritional, environmental, and other factors could also influence the rate of iron absorption and body iron load as shown in Table 1. In particular, the quantity and quality of iron entering the gastrointestinal tract could play a significant role in the overall absorption rate of body iron intake. Furthermore, dietary habits, such as the level of alcohol and water intake, as well as different food types and drugs, could also influence this process (Table 1) [23]. 
Table 1. Non-Regulatory Factors Affecting Iron Absorption.

\section{Quantitative aspects}

The quantity of iron present in the diet, e.g., excess iron intake in African siderosis or insufficient iron intake in vegetarian populations

\section{Qualitative aspects}

The form of dietary iron present in food, e.g., haem, ferrous, ferric, ferritin, hemosiderin

\section{Role of reducing agents}

The presence of reducing agents, e.g., ascorbic acid converts Fe (III) to Fe (II) and increases iron absorption

\section{Effect of dietary molecules}

The presence of dietary molecules with chelating properties, e.g., phytates and tannins decrease iron absorption

Effect of drugs with chelating properties

The presence of drugs with chelating properties, e.g., deferiprone, deferoxamine, tetracycline, hydroxyurea inhibit iron absorption

\section{Effect of fluids}

The quantity of water, alcohol, and other fluid intake can influence the dissolution of iron supplements or other components in the gastrointestinal tract

\section{Effect of molecules affecting cellular iron transport}

Dietary molecules and drugs affecting iron transport across the enterocyte (e.g., Nifedipine, which is an L-type calcium channel blocker)

Dietary factors affecting iron solubilisation

Dietary factors affecting the solubilization or precipitation of iron. Insoluble iron is not readily absorbed

Effect of $\mathbf{p H}$ on iron solubilisation
$\mathrm{pH}$ of the stomach and intestine, e.g., the higher the $\mathrm{pH}$ the lower the solubility of iron; Antacids
decrease iron absorption

\section{Anatomical changes and iron absorption}

Gastrectomy and other surgical interventions, which can affect gastrointestinal iron absorption. Body weight, e.g., obese people absorb less iron than normal body weight individuals

\section{Effect of diseases on iron absorption}

Malignancy, infectious and other diseases, haemoglobinopathies

Changes in iron absorption levels

Malnutrition, food poisoning, ageing

In general, vegetarian meals low in dietary iron are likely to reduce the intake of iron and rate of body iron load in vegetarian populations [39-41]. In contrast, in meat eating populations, sufficient amounts of iron are absorbed because of the presence of high concentration of haem, which is the main form of iron to be found in the meat dishes. Haem is a lipophilic iron complex with a protoporphyrin ring, which is better absorbed from the gastrointestinal tract than other forms of dietary iron [11].

\subsection{The Role of Proteins of Iron Metabolism in the Regulation of Iron Absorption}

Iron uptake from the gastrointestinal tract is regulated by several mechanisms and specific proteins. Modifications or abnormalities in the regulatory mechanisms can cause changes in the rate of iron absorption and overall body iron load. For example, increased iron absorption is observed in genetic diseases, such as hereditary haemochromatosis, and thalassaemia intermedia leading to iron overload in both conditions [42].

Under normal conditions there are several proteins and transcription factors that appear to play an important role in controlling the rate of iron transfer from the gastrointestinal tract to the blood stream. The regulatory control of iron absorption and utilization in the enterocyte includes several steps and pathways, which appear to involve a number 
of proteins such as ferrireductase(s), the apical divalent metal transported protein (DMT1), ferroportin, hepcidin, transferrin, and ferritin (Figure 1) [1-4,42-46].

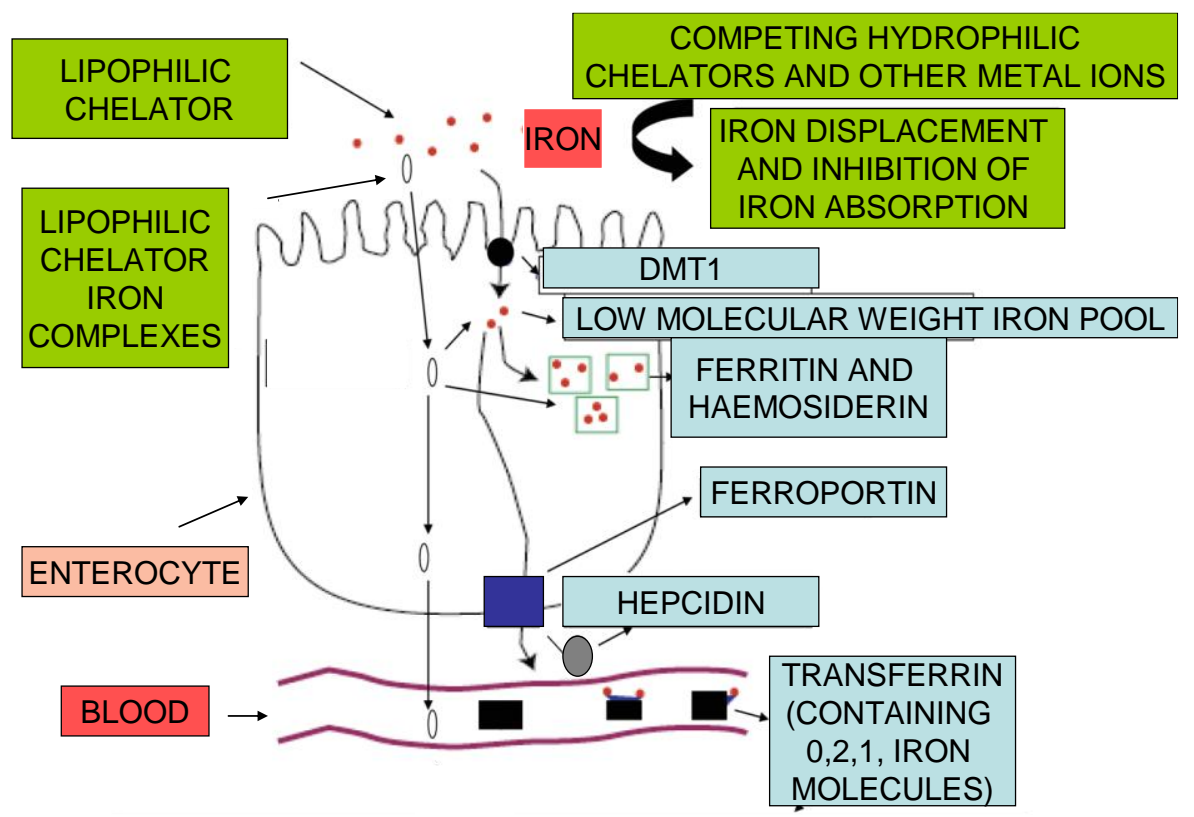

Figure 1. Mechanisms of iron absorption at the enterocyte. Animated image of the regulatory pathways involved in iron absorption. Iron metabolic pathways involving the apical divalent metal transported protein (DMT1), ferritin, hepcidin, ferroportin, and transferrin. A parallel, nonregulatory iron absorption pathway is also shown using lipophilic iron chelator complexes. In contrast to lipophilic chelators, hydrophilic chelators appear to inhibit iron absorption.

The initial step of the mechanism in the regulatory pathway of iron absorption is thought to involve the reduction of dietary ferric iron to ferrous iron by a ferrireductase at the surface of the enterocyte before its intracellular transport by DMT1 (Figure 1) [1-4]. Following intracellular entry in the enterocyte, iron is partly incorporated into ferritin or transferred into the low molecular weight, intracellular iron pool. In subsequent steps, iron is transported to ferroportin at the basolateral membrane of the enterocyte, which then exports it in plasma, where it is bound by transferrin. Iron bound by transferrin is then transferred to all of the cells of the body via an uptake mechanism by transferrin receptors present at the cell surface, followed by intracellular dissociation of iron from transferrin in an endosome of acidic $\mathrm{pH}[1-4]$.

Hepcidin, a protein hormone produced by the liver, is believed to play a major role in iron absorption [43]. Hepcidin is a key regulator of iron metabolism, controlling the release of iron into the circulation. In relation to iron absorption hepcidin can prevent the release of iron into plasma by binding ferroportin at the basolateral membrane of the enterocyte, causing its internalization and degradation within the enterocyte [43-48]. As a result, iron is not released into plasma, but remains trapped in the enterocytes and returns in the gut lumen since enterocytes are shed every 2-3 days. Several other pathways of iron metabolism could be affected by hepcidin, including the inhibition of iron release into plasma from macrophages [1-4,43]. Furthermore, these effects and also other related effects could influence the overall rate of iron loading and distribution in the body, including the haematopoietic tissues, leading among other things to iron metabolic imbalance conditions, such as IDA, the anaemia of chronic disease, and iron overload [1-4,42-48].

Iron absorption is also affected by changes in other regulatory molecules in addition to hepcidin. In particular, the expression of ferroportin and DMT1 appear to be affected by several other factors and to be different in the duodenum, haematopoietic tissues, liver, kidney, and also other organs [43-49]. In this context, several factors are involved, includ- 
ing the signal to the intestine to increase iron absorption, which appear to be influenced by regulatory molecules, which sense the iron stores $[1,49,50]$. Similarly, different regulatory mechanisms appear to control the production of haemoglobin in the haematopoietic tissues and to prevent anaemia. In this context, the regulatory peptide erythroferrone and the hormone erythropoietin play a key role in erythropoiesis and the regulation of iron absorption $[1,2,4]$. Overall, it appears that, in these cases, the influence of the regulatory molecules cause an increase in the expression of DMT1 and a corresponding increase in the uptake of iron $[1,49,50]$.

\subsection{Differences among Individuals in Iron Absorption Requirements}

The daily requirements for iron differ among individuals and depend on several parameters including age, sex, life style, sport activity, health status, etc. [15,29-32]. Most of the iron present in the body, which is estimated to be about $4-5 \mathrm{~g}$ in normal adults, is conserved and recycled. Of particular importance to iron metabolism and especially the haematopoietic activity, is the recycling of iron present in haemoglobin, which amounts to more than $60 \%$ of the total body iron content $[1,4,11,23]$. In contrast, only a few milligrams of iron are excreted or lost and these are replaced from dietary iron, which is a small component of variable amounts in different foods. However, it is envisaged that small loses of iron and insufficient intake of dietary iron over long periods will result in iron deficiency.

Under normal conditions, the absorption of iron in a western diet is generally estimated to be about $2 \mathrm{mg} /$ day and equivalent losses allow the maintenance of body iron balance. However, there are many different dietary variations between individuals and also populations worldwide (Table 1) [11,23].

Nutritional studies have suggested some general estimation for the daily iron requirements in different categories or groups of people. In adult men and post-menopause women, the daily requirement is about $8 \mathrm{mg}$, which is generally considered to be low in comparison to other groups. The highest daily requirement for iron is for pregnant women, which is about $27 \mathrm{mg}$, whereas for adult women is $18 \mathrm{mg}$, and for breastfeeding women, 9-18 mg. In comparison, the daily requirements of iron for teenage boys and girls is estimated to be about 11 and $15 \mathrm{mg}$, respectively [29,30,51].

Despite the differences in the daily iron requirements in each category, and each individual, the rate of body intake of iron could be affected by many other factors, and their combinations, including genetic predisposition, the erythropoietic activity of the bone marrow, the quantity and quality (haem or non-haem) of dietary iron, the presence of other dietary components, such as reducing agents, phytochelators, natural chelators, chelating drugs, and many others (Table 1) [29-31].

\section{Non-Regulatory Mechanisms of Iron Absorption}

Despite that major emphasis on the mechanisms of iron absorption is mainly associated with the regulatory role of proteins of iron metabolism, the overall rate of iron absorption is also governed by many dietary and other factors. Furthermore, the capacity of the protein regulatory pathway is limited and may not be effective under certain conditions.

\subsection{Dietary Molecules and Forms of Iron Affecting Its Absorption}

There are many dietary variations among individuals, groups, and populations, particularly in relation to iron availability in the consumption of meat or vegetarian foods. Haem iron is much better absorbed than other forms of iron and it is the main source of dietary iron found in meat containing foods, which predominate in western diets (Figure 2) [41]. In contrast to western populations, the most severe pathological complications in relation to IDA are observed in the malnourished and vegetarian populations of developing countries. In the latter populations, haem iron in the diet is, by comparison, much lower, and overall iron absorption is not in significant amount from other dietary forms found in vegetarian meals [23,36-41]. 
A

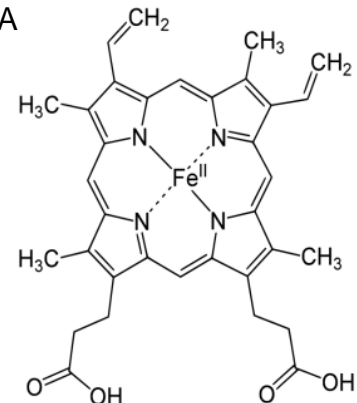<smiles>CC(=O)CC(O)(CC(=O)O)C(=O)O</smiles>

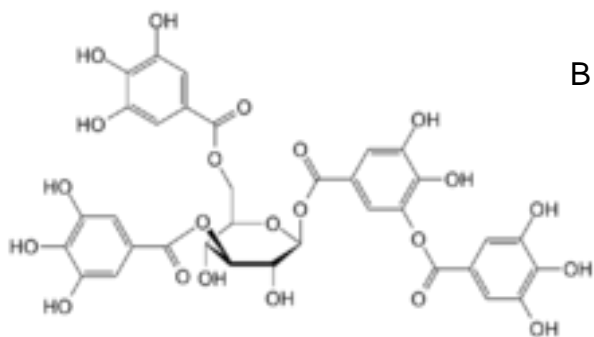

B

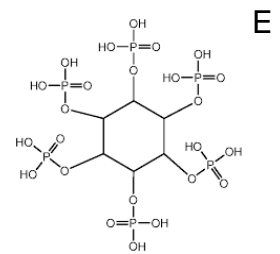<smiles>O=c1ccn(O)c(O)c1O</smiles><smiles>CC(=O)N(O)CCCCCNC(=O)CCC(=O)N(O)CCCCCNC(=O)CCC(=O)N(O)CCCCCN</smiles>

Figure 2. The chemical structure of molecules involved in iron absorption. Haem iron (A) is present in meat products and is better absorbed than non-haem iron. Tannic acid (B) and phytic acid (E) inhibit non-haem iron absorption. Citric acid (C) and ascorbic acid (D) facilitate non-haem iron absorption. The chelating drugs deferiprone (F) and deferoxamine (G) inhibit iron absorption.

Overall, it appears that in vegetarian and malnourished populations the rate of iron loss is higher than the rate of iron absorption from the iron present in vegetarian meals, resulting in a negative iron balance and, in the long-term, in iron deficiency [23].

One of the major factors influencing the rate of iron absorption is the apparent solubility of iron at the enterocyte site or possibly in other sections of the gastrointestinal tract, where iron may also be absorbed under different conditions (Table 1). The solubility of ferric iron in aqueous solution at physiological $\mathrm{pH}$ is negligible $\left(10^{-18} \mathrm{~mol} / \mathrm{L}\right)$ and iron precipitation rapidly occurs in biological fluids in the absence of low or high molecular weight naturally occurring chelators, such as citric acid and transferrin, respectively (Figure 2) [11].

In general ferrous iron is more soluble than ferric iron under the same conditions and is more readily absorbed. In general, ferrous iron forms or ferrous formulations, and the presence of reducing agents, such as ascorbic acid, will cause an increase in the solubility and overall absorption of iron from the enterocyte in comparison to most other ferric iron forms or formulations (Figure 2) [11,51,52]. In contrast, dietary molecules, such as tannins, phosphates, and other natural chelators or drugs, causing the precipitation of iron, will reduce the rate of iron absorption (Figure 2).

The interactions of iron with dietary molecules or drugs and their effects on iron absorption from the gastrointestinal tract could also be influenced by other essential or xenobiotic metal ions competing with iron $[11,23,28,53]$.

\subsection{Iron Chelating Drugs and Other Drugs Affecting Iron Absorption}

Many orally administered drugs, including iron chelating drugs, interact with iron in the gastrointestinal tract and affect iron absorption. In this context, the hydrophilic iron chelating drugs, deferiprone and deferoxamine, when used orally (Figure 2F,G) form hydrophilic chelator iron complexes, which do not facilitate the transport of iron in the enterocyte and other cells, and generally inhibit iron absorption (Figure 1) [53-56]. In particular, deferoxamine is widely used in the prevention of iron absorption in accidental iron poisoning $[55,56]$. 
The iron chelating drugs are widely used for the treatment of iron overload by increasing iron excretion in iron overloaded patients $[57,58]$. It is envisaged that dietary molecules with properties similar to deferiprone and deferoxamine will not only cause a decrease in iron absorption when administered orally, but also an increase in iron excretion and an overall negative iron balance. The prolonged administration of iron chelating drugs in non-iron loaded individuals is expected to cause a reduction in the body iron stores and low availability of iron to the haematopoietic tissues, leading to IDA.

There are many other orally administered drugs that can bind iron, but with lower affinity than the iron chelating drugs deferoxamine and deferiprone; in most of these, inhibition of iron absorption is expected including the cases of tetracycline, minocycline, and hydroxyurea. In addition, the absorption and bioavailability of these and other similar drugs, which form complexes with iron is also affected [59,60].

The interaction of dietary molecules and drugs with chelating properties on the absorption of iron has not yet been fully investigated. However, in these cases, competition for iron between dietary molecules and drugs is suspected. Furthermore, the possibility of formation of ternary mixed iron complexes between these molecules will also likely affect the absorption of iron [61].

\subsection{Quantitative Aspects of Iron Affecting the Rate of Iron Absorption}

A major factor affecting the rate of iron absorption in humans is the quantity of soluble iron forms present in the gastrointestinal tract (Table 1). In general, the amount of iron absorbed is to some extent proportional to the concentration of iron in food. This effect can be highlighted from some unusual cases of consumption of excess amount of iron. For example, African siderosis in rural Africa, the use of iron cooking utensils for the preparation of traditional sorghum-based beer led to progressive iron overload in a large number of individuals [62]. The possibility of excess iron absorption been caused by the presence of a genetic component or the high iron content of the traditional sorghum-based beer has also been considered. Similar cases of acute iron overload and toxicity from increased iron absorption is observed mainly in children as a result of accidental iron poisoning. In these cases large amounts of iron are rapidly absorbed, causing serious toxic side-effects that are sometimes fatal $[63,64]$.

It appears that with the increased iron uptake observed both in African siderosis and accidental iron poisoning, the normal regulatory pathways involving hepcidin and ferroportin are overwhelmed and unable to influence or control the increased rate of gastrointestinal iron absorption and associated toxicity [62-64]. Similar questions have been raised for the role of hepcidin and ferroportin in the slow reduction of excess iron in iron loaded transplanted thalassaemia patients, who have not received any form of iron chelation therapy $[52,65,66]$.

\section{Iron Formulations Used for the Treatment of Iron Deficiency Anaemia}

Many iron formulations are available and sold over the pharmaceutical counters worldwide for the treatment of IDA. The wide variety and selection of iron formulations is partly indicative of the commercial interest related to the large number of iron deficient patients worldwide, as well as the continuous efforts for the search and development of new, more effective, and less toxic iron complexes for IDA treatment. Usually the oral iron formulations are in a tablet, capsule, extended release tablet or capsule, or liquid preparations, which contain about $30-100 \mathrm{mg}$ of elemental iron.

The development of new and more effective iron formulations is also related to the increased and more selective requirements for more specific iron formulations by an increasing number of patients in addition to IDA, with other categories of anaemia not related to increased body iron requirements, such as pregnant women or vegetarian populations (Table 2) [52]. Many of these other categories of anaemic patients have a different pathophysiology and tolerance to iron formulations by comparison to IDA patients (Table 2) $[13,67,68]$. 
Table 2. Examples of anaemias treated with iron supplements.

$\begin{gathered}\text { Iron deficiency anaemia due to increased iron requirements } \\ \text { (e.g., pregnant and menstruating women, young children) }\end{gathered}$
Iron deficiency anaemia due to insufficient dietary iron
(e.g., vegetarian populations, malnutrition)

One major category involving millions of patients are those suffering from the anaemia of chronic disease or anaemia of inflammation, including patients with inflammatory, infectious and neoplastic diseases, such as different cancer types and inflammatory bowel disease. In most of the anaemia of chronic disease cases, sufficient iron is stored in the body, but compartmentalised in the reticuloendothelial system and cannot become readily available to the haematopoietic tissues for the production of sufficient amounts of haemoglobin $[67,68]$.

There are many and different iron formulation products available worldwide for the treatment of IDA and other anaemias. Despite the large number and long term experience with most of the available formulations, there is no satisfactory treatment in many cases and always a scope for improvement in the treatment of different categories of iron deficient patients. In this context, new patented iron formulations appear in the pharmaceutical markets at regular intervals claiming improved response in patients.

The risk/benefit assessment for the use of different iron formulations including ferrous, ferric, oral, intravenous, and slow release, in each disease category shown in Table 2 has not yet been fully examined or clarified. Furthermore, there is no general consensus among physicians in different countries for the use of any specific iron category of the available iron formulations.

However, the large selection of iron formulations can benefit patients experiencing toxicity with one of them, such as in the cases of gastric irritation, or low efficacy in iron absorption. In these cases new iron formulations can be selected and prescribed for better tolerance or higher efficacy. Furthermore, the selection of iron formulations in most European and other countries is subject to budgetary controls in public health institutions and the cheaper available product is usually selected by comparison to new patented iron formulations, which are, in most cases, very expensive [69].

Most of the ferric and ferrous iron formulation complexes used in IDA patients are based on naturally occurring sugar derivatives, which in general appear to partly increase the solubility of iron and facilitate its absorption from the gastrointestinal tract (Table 3) [70].

Several other non-sugar iron derivatives have also been used successfully for many years for the treatment of IDA (Table 3). Ferrous sulphate is one of the classic, non-expensive iron formulations, which has been widely used worldwide with satisfactory results in many patients $[71,72]$. Many investigators are also proposing the use of ferrous ascorbate for the treatment of IDA because of its high efficacy and low toxicity [73-77].

A new approach in the design and development of more effective and less toxic formulations containing iron complexes for IDA patients of different categories, is the use of iron trimaltol and other lipophilic iron chelator complexes, which were proposed many years ago, but only recently received approval for clinical use [25,78]. 
Table 3. Examples of iron complexes used for the treatment of iron deficiency anaemia.

\begin{tabular}{c} 
Ferrous iron formulations \\
(Ferrous sulphate, ferrous ascorbate, ferrous fumarate, ferrous gluconate, ferroglycine sulphate \\
Ferric iron formulations \\
(Ferric fumarate, ferric polymaltose, iron dextran, ferric gluconate, ferric iron sucrose, ferric \\
saccharate, iron bis-glycinate chelate \\
Ferric intravenous iron formulations \\
(Iron sucrose, ferric carboxymaltose, ferric gluconate, ferumoxytol, iron isomaltoside-1000, iron \\
dextran (low-molecular-weight forms) \\
\hline $\begin{array}{c}\text { Lipophilic (hetero)aromatic iron complex formulations } \\
\text { (Ferric maltol, ferric 8-hydroxyquinoline, ferric tropolone, ferric } \\
\text { 2-hydroxy-4-methoxypyridine-1-oxide (L6) }\end{array}$
\end{tabular}

\section{The In Vitro Properties of Iron Maltol and Other Lipophilic Iron Complexes}

Many ferrous and ferric formulations are widely used and sold at pharmacies for the treatment of IDA, but most of these have a low therapeutic index and are not satisfactory because of low efficacy, and are frequently non tolerated, leading to poor compliance (Table 3). The concept of the introduction of new, more specific iron formulations with a higher therapeutic index, including the use of iron maltol and other lipophilic iron chelator complexes for the treatment of IDA, was initiated about 40 years ago [25]. In particular, the trimaltol iron complex was originally designed, synthesised, and screened in vitro and in vivo in 1980-1981, by one of the authors (G.J.K.), following his discovery of the novel alpha-ketohydroxyheteroaromatic (KHP) class of iron chelators (1978-1981), which were intended for clinical use in iron overload and other iron metabolic disorders, including the treatment of IDA [25]. The slow progress in the development of iron maltol and other lipophilic iron chelator complexes appears to be related to commercial considerations $[69,79]$.

\subsection{Physicochemical Properties of Lipophilic Chelators and Their Iron Complexes}

An original screening system for identifying investigational new drugs (IND) for the treatment of iron metabolic disorders, including iron overload and IDA, was previously tested using a large number of known and new chelators and chelator iron complexes [25]. Many in vitro and in vivo procedures were involved in the screening process, including the physicochemical characterisation of the chelators and their iron complexes. In general, the physicochemical properties, such as the size, charge, and lipid/water partition of molecules affect their mode of action, including gastrointestinal absorption, membrane transport, and tissue distribution. In particular, IND of small size molecular mass, neutral charge, and high lipophilicity appear to facilitate passive transport across cell membranes.

Within this context, several physicochemical parameters of IND and their metal complexes could be investigated and predict, to some extent, related pharmacological activity. These parameters include the affinity of the chelators for iron and other metals, the stability and stoichiometry of their complexes at acidic and physiological $\mathrm{pH}$, the solubility, charge, the lipid/water partition coefficients of the chelators and their iron complexes, etc. [25,57]. Examples of some physicochemical properties of chelating drugs, phytochelators, and other synthetic chelators, as well as their iron complexes, are shown in Table 4.

There is wide variation in the physicochemical parameters of both the chelators and their iron complexes. The differences between each chelator reflected in the parameters are the results of the structural features, metal binding ligands, and other side chains or substituents in the main structure of the chelator molecules. Similar differences in physicochemical parameters, including the charge, partition coefficient, and molecular mass are also observed among the chelator iron complexes (Table 4) [25,57].

All the chelators listed in Table 4, including maltol and deferiprone, form a 3:1 stoichiometry chelator: iron complex at physiological $\mathrm{pH}$, with exception of deferasirox 
and deferoxamine, where 2:1 and 1:1 stoichiometry complexes are formed, respectively (Figure 2).

Table 4. Physicochemical properties of chelators and their iron complexes.

\begin{tabular}{ccccccc}
\hline Chelator & Log $\beta$ & MWt & Kpar & Charge & Kpar Iron & $\begin{array}{c}\text { Charge } \\
\text { Complex }\end{array}$ \\
\hline Maltol & 30 & 126 & 1.23 & neutral & 0.32 & neutral \\
\hline Tropolone & 32 & 122 & 3.04 & neutral & 4.50 & neutral \\
\hline 8-Hydroxyquinoline & 37 & 145 & 28.30 & neutral & 10.00 & neutral \\
\hline L3 & 30 & 127 & 0.09 & zwitterionic & 0.04 & neutral \\
\hline L4 & NA & 111 & 0.09 & zwitterionic & 0.95 & neutral \\
\hline L6 & 29 & 155 & 0.37 & zwitterionic & 4.85 & neutral \\
\hline Omadine & NA & 127 & 0.04 & zwitterionic & 2.67 & neutral \\
\hline Mimosine & 36 & 198 & 0.01 & zwitterionic & 0.01 & zwitterionic \\
\hline Deferoxamine & 31 & 561 & 0.02 & positive & 0.02 & positive \\
\hline Deferiprone & 35 & 139 & 0.18 & neutral & 0.05 & neutral \\
\hline Deferasirox & 27 & 373 & 6.30 & negative & NA & negative
\end{tabular}

Iron complex stability constants ( $\log \beta)$; molecular weight (MWt); n-octanol/water partition coefficients (Kpar); charge of chelator and chelator iron complex at physiological $\mathrm{pH}$ (charge); 2,4-dihydroxypyridine-1-oxide (L3); 2-hydroxypyridine-1-oxide (L4); 2-hydroxy-4-methoxypyridine-1-oxide (L6). Not available (NA).

\subsection{In Vitro Properties of Maltol and the Maltol Iron Complex}

Maltol is a naturally occurring alpha-keto hydroxy pyrone compound found in plants, e.g., in the bark of the larch tree and in pine needles [80]. It is also found in roasted malt and in bread, and is formed during caramelization. Maltol has been widely used and marketed for more than 50 years as a flavour enhancer and as a food additive. It is rapidly and extensively absorbed from the gastrointestinal tract (similar to ethyl maltol—an analogue of maltol) and both are mostly metabolised to glucuronide conjugates [81] (Figure 3).
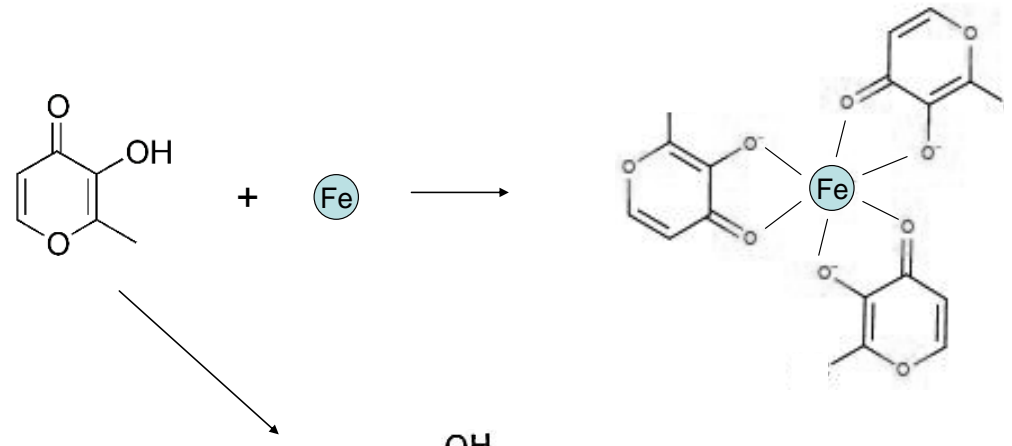<smiles>Cc1occc(=O)c1O[C@H]1OC(C(=O)O)C(O)C(O)C1O</smiles>

Figure 3. The formation of the tris-maltol iron (III) complex and maltol glucuronide. At physiological $\mathrm{pH}$, maltol reacts with iron (III), forming the tris-maltol iron octahedral complex with iron in the centre. During iron (III) binding, a proton is displaced from the hydroxyl group of each maltol molecule, forming a negatively charged molecule, which coordinates with iron (III) of 3+ charge, forming a neutral trimaltol iron (III) complex. In humans, maltol is mostly metabolised to the maltol glucuronide conjugate, which has no iron or other metal chelating capacity. 
Maltol was first identified as a potential iron chelator during the period of the fourstep synthesis of the iron chelating drug deferiprone, where it was used as the starting material [25]. It was included in the list for the in vitro and in vivo screening procedure of natural and synthetic chelators intended for potential clinical use in iron overload, iron deficiency, and other diseases of iron metabolism [25,57]. The alpha-keto hydroxy iron binding site of maltol is identical to that of the chelating drug deferiprone (Figure 2F).

The in vitro screening procedure of the chelators involved the study and characterisation of iron complex formation, the interaction with proteins of iron metabolism, and the iron transport effects in red blood cells (RBC), as well as the iron transport effects in rat jejunum permeation $[25,57]$.

In the iron binding studies, a 3 maltol: 1 iron stoichiometry complex (trimaltol iron) was formed at physiological pH using the Job's plot method as indicated in Figure 4B [25]. While maltol is a white solid, forming a colourless solution, the iron complex of maltol is of deep red/orange colour, and appears stable at a wide $\mathrm{pH}$ range, including the pH 5-9 range, as shown in Figure 4A [25].

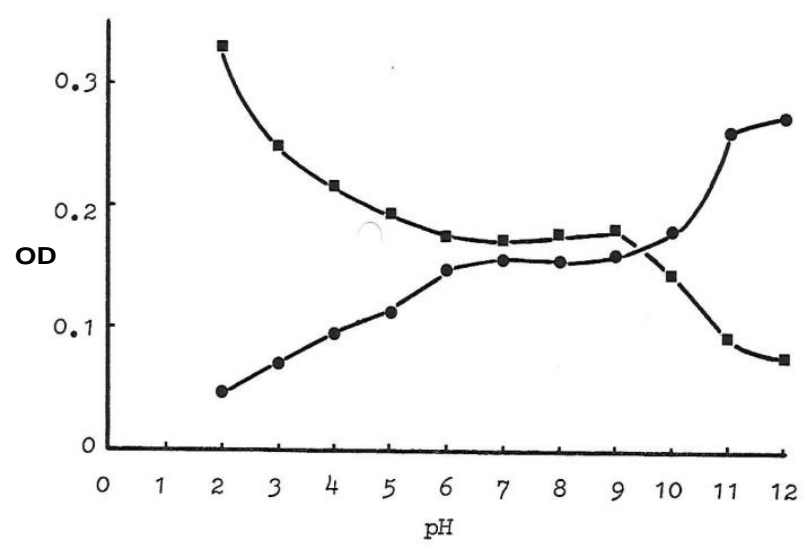

(A)

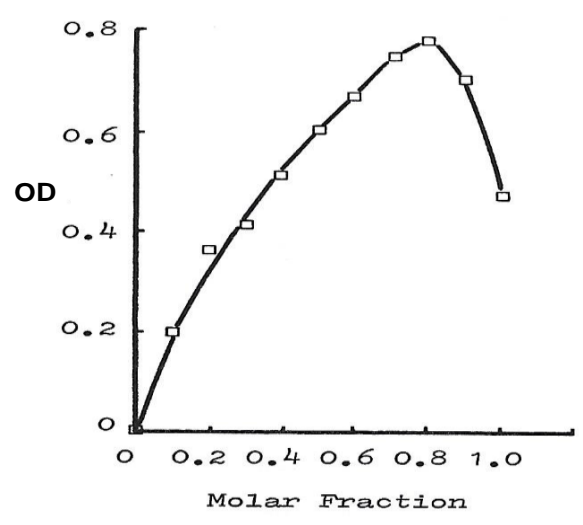

(B)

Figure 4. Characterisation of the maltol iron complex. (A) Stability of the maltol iron complex over a wide $\mathrm{pH}$ range. Titration of a mixture of maltol $(0.75 \mathrm{mM})$ and iron $(0.25 \mathrm{mM})$ at a $\mathrm{pH}$ range 2-12, indicating one iron complex species of red/orange colour at the $\mathrm{pH}$ 6-10 range. The optical density (OD) monitoring was carried out at the wavelengths of $320 \mathrm{~nm}$ (circles) and $280 \mathrm{~nm}$ (squares) [25]. (B) Identification of the stoichiometry of the tris-maltol iron complex at physiological $\mathrm{pH}$. Estimation of the stoichiometry of the maltol iron complex using the Job's plot method. Measurement of the optical density (OD) at $220 \mathrm{~nm}$ of different molar fraction mixtures of maltol $(1 \mathrm{mM})$ and iron $(1 \mathrm{mM})$ at $\mathrm{pH}$ 7.0. The horizontal axis refers to the molar fraction of maltol. 
An octahedral structure iron complex similar to deferiprone and other bidentate chelators is formed in the interaction of maltol with iron at physiological $\mathrm{pH}$ (Figures 3 and 4). A proton is released from the coordinating hydroxyl group of maltol on binding ferric (3+) iron, forming three negatively charged maltol molecules (Figures 3 and 4 ) and an overall neutral trimaltol ferric iron complex. Both maltol and the maltol iron complex are lipophilic and have a neutral charge at physiological $\mathrm{pH}$ (Table 4).

\subsection{Interactions of Maltol and the Maltol Iron Complex with Proteins}

The pharmacological activity of maltol and the maltol iron complex is affected by a variety of proteins, including proteins involved in iron metabolism [28,57]. In particular, the interaction of maltol and the maltol iron complex with the iron transport protein transferrin and the iron storage proteins ferritin and haemosiderin is a major parameter characterising the mode of action of chelators, and is also a key part of the chelator evaluation for clinical use in diseases related to iron metabolism [19-22,24,25,28,57,82-85].

Substantial differences were observed in the original studies of iron mobilisation from diferric transferrin using maltol and other KHP chelators in vitro $[25,86]$. The 59-Fe radioactive labelled iron transferrin equilibrium dialysis studies have indicated that maltol is not effective in the mobilisation of iron from diferric transferrin. For example, in four different experiments for up to six hours, iron release from 59-Fe radioactive labelled diferric transferrin using deferiprone $(4.0 \mathrm{mM})$ was $77-90 \%$, and using maltol $(4.0 \mathrm{mM})$ was $4-23 \%$ at the same conditions $[25,86]$. More iron was released from transferrin by maltol at $24 \mathrm{~h}$ incubations. However, UV-visible spectroscopic changes have also suggested that a ternary complex is formed between transferrin, iron, and maltol, but the maltol iron complex is not readily dissociated from transferrin (Figure 5) $[25,86]$.

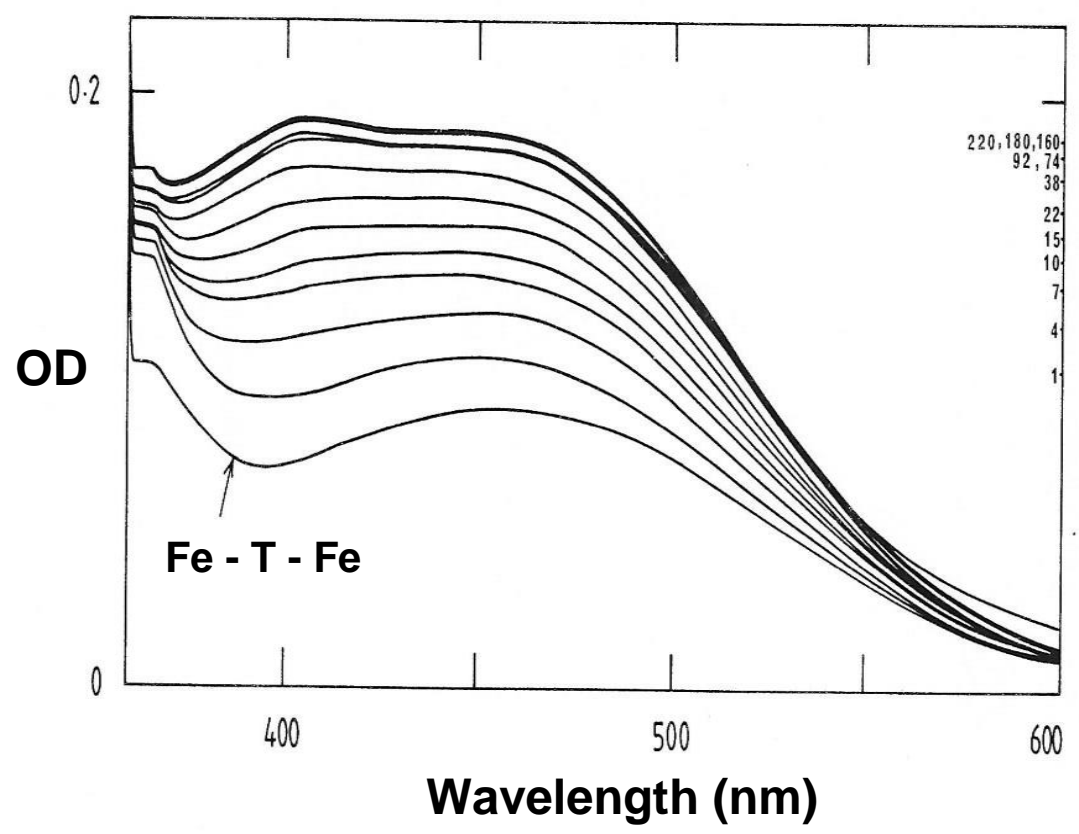

Figure 5. The interaction of maltol with iron saturated transferrin. Optical density (OD) spectral changes of the reaction of maltol $(1.0 \mathrm{mM})$ with diferric transferrin (Fe-T-Fe) $(0.036 \mathrm{mM})$ as a function of time from 1-220 $\mathrm{min}[25]$.

Similar results were obtained in iron mobilisation studies from diferric lactoferrin. For example, in equilibrium dialysis studies using 59 -Fe radioactive labelled diferric lactoferrin iron release at $\mathrm{pH} 7.3$ using deferiprone $(0.29 \mathrm{mM})$ was $87.4 \%$, and using maltol under the same conditions was $9.4 \%$ [87].

Under normal conditions, transferrin iron saturation in humans is only about $20-30 \%$, with apo-transferrin, the most prominent species in blood by comparison to the two 
monoferric transferrins and diferric transferrin $[17,18]$. Apo-transferrin has high potency in mobilising mononuclear and low molecular weight iron, thus preventing microbial growth and the catalytic production of toxic free radicals, both requiring the presence of iron [88].

Apo-transferrin also has the capacity to mobilise iron from low molecular weight iron complexes, including iron from citrate, deferiprone and maltol iron complexes in plasma [88-90]. In this context, maltol or deferiprone iron complexes facilitate the transfer of iron to apo-transferrin, forming diferric and monoferric transferrin, which are then taken intracellularly through transferrin receptors in haematopoietic and other tissues [91-95].

In the initial studies of the interaction of maltol with ferritin, it was shown that maltol $(1-4 \mathrm{mM})$ was effective in the mobilisation of ferritin iron $(0.6-1.8 \mathrm{mM})$ at a slow rate reaction, which reached about 3 days to completion. It was estimated that the amount of iron released from ferritin by maltol $(1.0 \mathrm{mM})$ at the end of the reaction was $24 \%$ by comparison to deferiprone $46 \%$, used under the same conditions [25,96]. In further studies with maltol and other chelators, iron mobilisation from ferritin was confirmed and was also extended and shown to take place from other polynuclear forms of iron, such as haemosiderin and freshly prepared iron precipitates [97]. The rate of iron solubilisation from polynuclear forms of iron was higher in freshly prepared iron precipitates by comparison to haemosiderin and less so from ferritin [97]. Furthermore, less iron has been shown to be mobilised by maltol and other chelators from ferritin and haemosiderin possessing lower amounts of iron [98].

Similar results were observed in equilibrium dialysis $24 \mathrm{~h}$ studies using $59-\mathrm{Fe}$ labelled horse spleen ferritin $(0.15 \mathrm{mg} / \mathrm{mL})$ containing 2200 molecules of iron per ferritin molecule and different chelators $(1.2 \mathrm{mM})$. Under these conditions maltol caused the release of $9 \%$ of iron by comparison to deferoxamine $12 \%$ and deferiprone $21 \%$ [99].

The interaction of maltol and the maltol iron complex has also been investigated in other proteins of iron metabolism. In particular, maltol in a comparative study with the iron chelating drugs deferoxamine and deferiprone, as well as other compounds has been shown to inhibit the iron containing proteins lipoxygenase and cyclooxygenase, and associated metabolic pathways, such as thromboxane A2 synthesis and the conversion of arachidonate to HETE and HPETE in platelets [100-102]. The inhibitory effect of maltol in both cases was concentration dependent, reversible in the addition of iron, and lower by comparison to deferiprone and deferoxamine [100-102]. In the case of the thromboxane A2 inhibition, the median inhibitory concentration (IC50) was about $8 \mathrm{mM}$ for maltol, $0.7 \mathrm{mM}$ for deferoxamine, and $0.2 \mathrm{mM}$ for deferiprone. Similarly, in the conversion of arachidonate to HETE and HPETE was $8 \mathrm{mM}$ for maltol, $1.2 \mathrm{mM}$ for deferoxamine, and $1.6 \mathrm{mM}$ for deferiprone [101,102].

Overall, it appears that the interactions and effects of maltol with proteins of iron metabolism are concentration dependent and involve several components. In particular, maltol has the ability to mobilise intracellular low molecular weight iron, ferritin, and haemosiderin iron forming trimaltol iron complexes. Furthermore, trimaltol iron complexes can interact and donate iron to apo-transferrin and form monoferric and diferric transferrin, which subsequently can release iron to cells for storage, haemopoiesis, or utilisation for other cellular functions.

\subsection{The Antioxidant Effects of Maltol and Other Iron Chelators}

Iron is the major catalyst of free radical reactions and oxidative stress toxicity in biological systems. Many factors influence the rate of free radical reactions catalysed by iron in biological systems, including the $\mathrm{pH}$, the presence of reducing agents, and of chelating agents [103-106].

The pro-oxidant and antioxidant effects of drugs are major parameters characterising their mode of action, as well as their toxicological and pharmacological properties. The modulation of free radical toxicity is more sensitive in the presence of iron and copper chelating drugs, which can strongly influence the catalytic activity of these metals [106-109]. 
The first antioxidant studies in relation to maltol have been carried out in 1986 [110]. Maltol and other chelators intended for clinical use have been tested in an original screening system involving three different models of free radical toxicity. In the first model, the iron induced free radical damage on the sugar component of DNA, deoxyribose, was carried out by monitoring malondialdehyde formation. Inhibition of deoxyribose damage was concentration dependent and ranged 1-4 mM in the case of maltol (49-80\%) and 1-2 mM in the case of deferoxamine (90-91\%) and also deferiprone (53-80\%) [110]. In contrast, EDTA promoted free radical formation and caused an increase in deoxyribose damage at the same range of concentration (1-4 mM) and under the same conditions. In another model of free radical damage using UV irradiation on IgG, which resembles the formation of immunocomplexes of IgG in inflammation, the inhibitory effect of maltol $(0.05-0.1 \mathrm{mM})$ was moderate (3-22\%). In the third model of lipid peroxidation, the breakdown product malonaldehyde was monitored in mouse skeletal muscle homogenates resembling tissue damage, which is observed in many clinical conditions, such as muscular dystrophy, thalassaemia, and cancer. Under these conditions, maltol $(0.5 \mathrm{mM})$ has been shown to exert antioxidant effects and to cause 79\% inhibition [110]. Similarly, 13 other chelators have also been tested causing variable inhibition ranging from $99 \%$ maximum with deferiprone and 17\% minimum with 8-hydroxyquinoline [110].

Following the above findings, the antioxidant activity of maltol has also been studied in several other free radical models [99-101,110]. Further studies followed where maltol as a food component or flavour enhancer has also been identified to possess potent antioxidant properties [111-116]. The potential application of maltol as a therapeutic antioxidant has also been identified in several disease models, including the treatment of inflammatory conditions, colitis, hepatotoxicity, diabetic peripheral neuropathy, carbon tetrachloride poisoning, etc. [117-122].

Studies on the pro-oxidant effects of iron complexes have also confirmed that ferrous sulphate, but not the trimaltol iron complex, promotes lipid peroxidation [110,123]. In general, it appears that maltol under physiological conditions can inhibit the catalytic formation of free radicals and lipid peroxidation caused by iron, and that the trimaltol iron complex does not exhibit pro-oxidant effects [99-101,110-116,123].

\section{Cell Studies Using Maltol and Other Chelator Iron Complexes}

The transport of chelators and chelator iron complexes across cell membranes provides important pharmacological information and is an important parameter in the screening procedure for use in iron metabolic diseases, including IDA.

The interaction of chelator iron complexes with transferrin and utilisation of iron from the chelator iron complexes by haematopoietic and other cells for the production of haemoglobin are major factors contributing to the efficacy of iron formulations intended for the treatment of IDA $[16,25,42]$.

Iron transfer, donation, utilisation, and exchange differ among chelator iron complexes and various cell types, including cell lines. Within this context, different cell studies have been initiated in the original screening system and continue until today for clarifying the mechanisms and mode of action of the maltol iron complex in the treatment of IDA [25].

\subsection{Iron Transport by Maltol and Other Chelators in Matured Red Blood Cells}

The identification of the suitability of the maltol iron complex for the treatment of IDA was first realised in matured RBC experiments by measuring the incorporation of iron following incubation of RBC with maltol iron and other chelator iron complexes [25].

The transfer of iron by maltol and other chelators in RBC was monitored using radioactively labelled iron (59-Fe). In a number of experiments under different conditions, the transfer of iron and incorporation in $\mathrm{RBC}$ by maltol proceeded rapidly and reached equilibrium within $30-40 \mathrm{~min}$. About $40-60 \%$ of the iron (59-Fe) was incorporated in RBC and the remaining maltol iron (59-Fe) complex remained in the supernatant (Figure 6) [25]. 


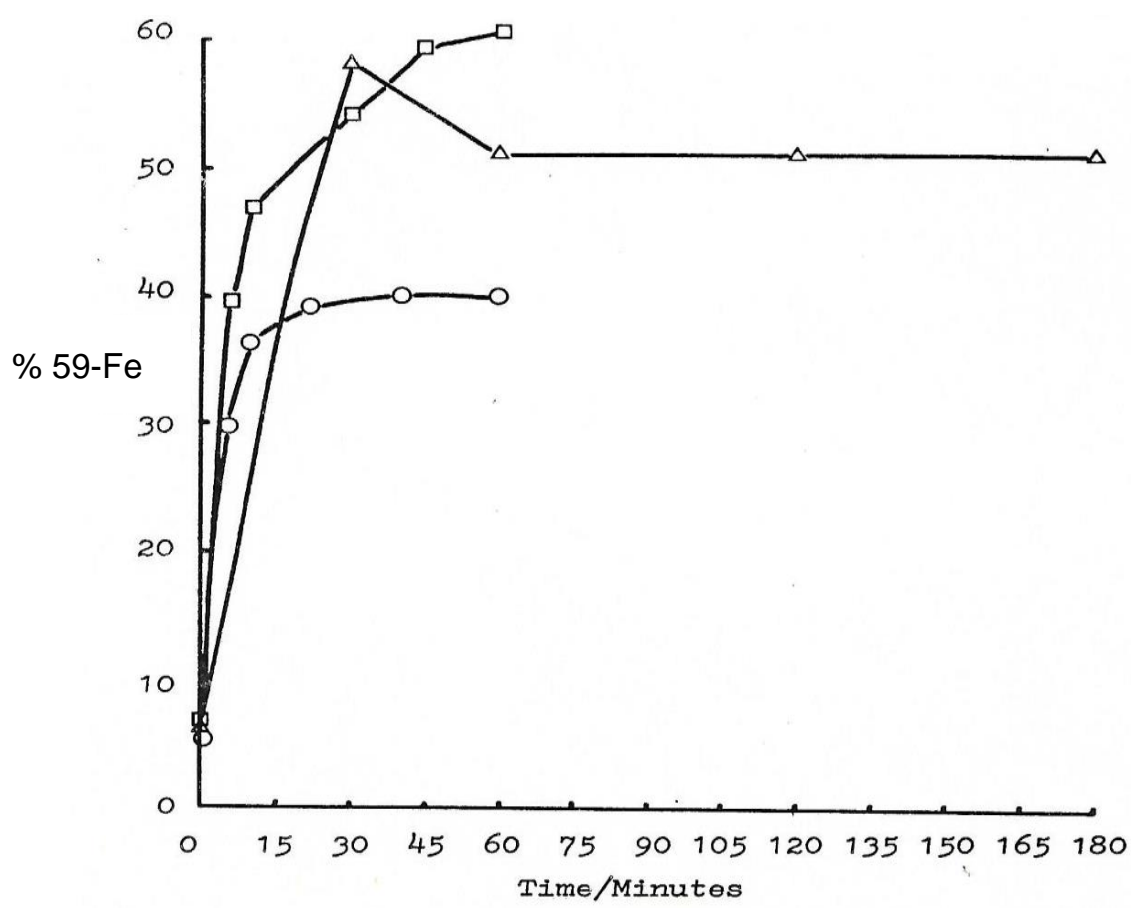

Figure 6. The transfer of iron by maltol in red blood cells. The rate of incorporation of the iron (59-Fe) in red blood cells was measured at different time intervals, following incubation with the iron (59-Fe) maltol complex at physiological $\mathrm{pH}$. Three different experiments were carried out using different conditions including different buffers and variable maltol concentrations $(0.5-4.0 \mathrm{mM})$ with molar excess ranging from 75 to 2800 times over iron [25].

By comparison and under the same conditions iron incorporation in RBC was less than $5 \%$ in the presence of the hydrophilic chelator iron complexes of deferiprone, deferoxamine, and 1,4-dihydroxypyridin-1-oxide (L3) (Kpar 0.02-0.05) (Table 4). In contrast, similar amounts of iron incorporation of about $50 \%$ in matured RBC to that of the maltol iron complex (Kpar 0.32) was observed with 2-hydroxy-4-methoxypyridine-1-oxide (L6) (Kpar 4.8) (Table 4) [25].

In much more extensive RBC studies of up to $3 \mathrm{~h}$ duration involving 19 chelators with a wide range of physicochemical properties, including Kpar of chelator iron complexes, several lipophilic iron complexes have been identified to be better transporters of iron into RBC than maltol [124]. The lipophilic iron complexes of tropolone, 8-hydroxyquinoline, and omadine with Kpar of 4.7, 10.0, and 2.7, respectively, caused an increased RBC uptake of iron $(59-\mathrm{Fe})$ in the range of $80-90 \%$ by comparison to maltol iron (59-Fe) complex of about $50 \%$ (Table 4) [124]. Increased RBC uptake of iron (59-Fe) was also observed in similar experiments using lipophilic analogues of deferiprone [125].

It appears that, in general, lipophilic iron chelator complexes with neutral charge, including the maltol iron complex, readily diffuse across RBC membranes and incorporate iron in cellular compartments. In contrast, hydrophilic iron complexes, including those of deferiprone and deferoxamine, do not facilitate the transfer of iron across RBC membranes. Similar iron transfer properties using maltol and similar lipophilic chelator iron complexes are also expected in other cell types.

\subsection{The Role of Chelators in the Uptake and Intracellular Distribution of Iron in Erythroid Cells}

The transfer and distribution of iron in all the cells of the body under normal conditions is accomplished primarily by the plasma protein transferrin. The interactions of transferrin iron with chelators extracellularly and intracellularly appear to influence the intracellular distribution of iron. Furthermore, it is also expected that chelators could transfer iron in cells independently from transferrin and influence the intracellular distribution of iron. 
Investigations regarding the iron metabolic pathways involved in the uptake and intracellular distribution of iron (59-Fe) from hydrophilic and lipophilic chelators of different physicochemical properties and transferrin iron have been carried out in erythroid cells in vitro. In studies using K562 cells or human bone marrow cells, iron (59-Fe) uptake into cells from lipophilic chelators, such as tropolone, 8-hydroxyquinoline, and maltol was many times higher than hydrophilic chelators, such as deferiprone, mimosine, and deferoxamine [126]. In particular, iron (59-Fe) uptake in bone marrow cells from these lipophilic iron complexes was about $40 \%$ times higher by comparison to transferrin iron (59-Fe) [126].

The uptake of iron by erythroid cells from lipophilic iron complexes was delivered in significant amounts in both haem and ferritin and none of the chelators has shown exclusive delivery to, or rejection of, a particular pathway, associated either with haem production or ferritin iron incorporation [126].

Similar results of iron uptake from lipophilic iron complexes were observed in a separate set of $24 \mathrm{~h}$ studies in K-562 and U-937 cells by 8 chelators, including maltol $(0.6 \mathrm{mM})$ [127]. In addition to iron uptake in K-562 and U-937 cells, several other iron metabolic pathways were examined in the presence of chelators and their iron complexes, including transferrin membrane binding, DNA synthesis, and overall toxicity to cells, all of which appear to interfere with iron and other metabolic processes [127].

Transferrin iron uptake is usually regulated by the number of transferrin receptors present on the cell membrane of each cell $[1,16,19,26]$. Furthermore iron chelating drugs appear, in general, to cause reduced iron availability and increased transferrin receptor synthesis. In this context, $24 \mathrm{~h}$ incubation with most chelators, including maltol and deferiprone, but excluding the cytotoxic omadine and 8-hydroxyquinoline caused in both K-562 and U-937 cells lines, increased transferrin cell binding and, presumably, transferrin receptor synthesis. Similarly, under the same conditions, DNA synthesis was supported especially in the case of maltol [127]. The safety of maltol and the maltol iron complex was also confirmed in other cell viability and DNA synthesis studies using 14 chelators $(0.02 \mathrm{mM})$ in the leukaemic cell lines K-562, U-937, HL60, and ML2. In contrast, under similar conditions, and even at lower concentrations, the lipophilic chelators and iron complexes of omadine, 8-hydroxyquinoline, and tropolone exhibited cytotoxic and DNA synthesis inhibitory effects [128].

It appears that chelators and chelator iron complexes cause variable effects on cellular iron metabolic pathways and, in some cases, selective cytotoxicity. In general, hydrophilic and moderate lipophilic chelator and chelator iron complexes, including maltol and the maltol iron complex, are less cytotoxic than lipophilic chelators and chelator complexes.

\subsection{The Antimicrobial Effects of Maltol and Other Chelators}

All living cells, including microbes, require iron for growth and development. Microbes synthesise specific chelators, termed siderophores, for the sequestration of iron from the surrounding medium [24,129-133]. The interaction of microbial cells with chelators and chelator iron complexes could, in principle, influence microbial growth. In this context, natural dietary chelators or drugs with chelating properties could act as siderophores by donating iron and promoting microbial growth $[88,134,135]$. In contrast, transferrin, lactoferrin, and other natural or synthetic chelators and chelator iron complexes could have the opposite effect and withdraw or prevent the uptake of iron from microbes, thus inhibit microbial growth [88,136-138].

In a number of experiments, the effect of maltol $(0.35 \mathrm{mM})$ and the maltol iron complex on the growth of various types of bacteria in human serum was examined and compared to the chelating drugs deferoxamine $(0.2 \mathrm{mM})$ and deferiprone, as well as four other KHP chelators $(0.35 \mathrm{mM})$ [139]. Maltol was the only chelator that inhibited all four bacteria species, namely Y. enterocolitica (17\%), S. epidermitis (14\%), E. coli (39\%), and P. aeruginosa $(13 \%)$. In contrast, deferoxamine promoted the growth of three bacteria species (23-56\%) 
and only inhibited E. coli (20\%). By comparison, deferiprone inhibited the growth of three bacteria species (18-53\%) and promoted the growth of S. epidermitis (10\%) [139].

The effect of maltol was also investigated in relation to the growth of $P$. falciparum in a series of experiments for the identification of IND, to combat widespread multiple drug resistance in human malaria [140]. Maltol inhibited the growth of P. falciparum by about $15 \%$ at $0.01 \mathrm{mM}$ and $50 \%$ at $0.10 \mathrm{mM}$ by comparison to control. By comparison, deferiprone caused $52 \%$ and $87 \%$, and deferoxamine $1 \%$ and $99 \%$ inhibition, using the same concentrations and conditions as maltol. Five other KHP chelators were also tested and showed to be more effective inhibitors (70-97\%) than maltol at $0.10 \mathrm{mM}$ [140].

Macrophages play a key role in iron metabolic processes, including the rapid turnover of iron due to the catabolism of effete RBC in the spleen and the liver, and in relation to antimicrobial activity. The effect of iron chelators on macrophage iron uptake and release could influence many processes, including antimicrobial activity. A study using mouse peritoneal macrophages and KHP chelators has shown that maltol enhanced iron mobilisation from macrophages pulsed with 59-Fe-transferrin-antitransferrin immune complexes [141]. Iron (59-Fe) release by maltol was higher than deferoxamine. Deferiprone and 1-ethyl-2-methyl-3-hydroxypyrid-4-one (L1NEt) were markedly more effective than deferoxamine, maltol, or mimosine. The release of iron $(59-\mathrm{Fe})$ from macrophages increased with increasing chelator concentration above $0.008 \mathrm{mM}$ and time of incubation from 2 to $14 \mathrm{~h}$. None of the chelators appeared to donate significant amounts of iron to macrophages, and none showed any cytotoxic effects [141].

Overall it appears that maltol and its iron complex do not appear to promote microbial growth. Similarly, the macrophage studies suggest that the maltol iron complex, as well as other KHP complexes, do not appear to be recycled through the reticuloendothelial system [139-141].

\subsection{Uptake of Iron Maltol by the Enterocyte}

Maltol and other lipophilic chelators were first identified as potential IND for increasing iron absorption in the original $\mathrm{RBC}$ and rat jejunum permeation screening studies of phytochelators and synthetic chelators, with potential for clinical use in IDA. The investigations were carried out at the same time as the screening of KHP and other chelators, which were intended for the treatment of iron overload and other diseases of iron metabolism. The latter investigations led to the identification of the iron chelating drug deferiprone, which has been used in iron loaded patients since 1987 [25,142,143].

In the in vitro rat jejunum permeation screening studies, the lipophilic KHP chelators selected for investigation were used at a six molar ratio excess over iron $(0.01 \mathrm{mM})$. In these studies maltol and L6 were identified to be 2.5 and 5.0 times more effective than the phytochelators catechol and citrate, respectively, in the transfer of iron (59-Fe) across the inverted jejunum sac. Furthermore, in the same studies, the L6 iron (59-Fe) complex was shown to be partitioning in the intestinal tissue to a greater extent than the maltol and also the other iron complexes [25].

Increased iron uptake across the small intestine of the rat from the maltol iron complex was observed in confirmatory subsequent studies [143]. Overall, it appears from the original rat jejunum permeation studies in vitro that maltol and other lipophilic chelator iron complexes can be taken by the intestinal tissue and transferred across the intestinal wall, thus facilitating iron absorption $[25,143]$.

\section{In Vivo Studies of the Effect of Maltol and Other Chelators on Iron Absorption}

Under normal conditions, the rate of iron absorption is controlled in the enterocyte by a regulatory pathway involving ferroportin and hepcidin (Figure 1) [1-4,43-48]. However, under certain conditions, e.g., in African siderosis and accidental iron poisoning, the normal regulatory pathway appears to be overwhelmed and cannot control or influence the increased rate of gastrointestinal iron absorption [62-64]. Similarly, the rate of iron absorption 
appears to be influenced by the presence of iron chelators and other factors, which are separate from the regulatory pathway involving ferroportin and hepcidin [23,43-48].

\subsection{Increase in Iron Absorption in Animals Using Maltol and Other Lipophilic Chelators}

Natural and synthetic iron chelating compounds are known to influence the absorption of iron and some of them may have a use in the treatment of diseases associated with gastrointestinal iron absorption imbalance, which may lead to IDA or iron overload, e.g., idiopathic haemochromatosis and thalassaemia intermedia [23,28,42,54-58].

Following the original investigations and identification of chelators for potential use in the treatment of IDA, an in vivo screening system was developed using chelator iron (59-Fe) complexes uptake and body distribution in mice [25,144]. In this context, the effect of 17 natural and synthetic chelators on iron (59-Fe) absorption in mice has been investigated in three different experiments using single and repeated intragastric administrations of chelator iron (59-Fe) complexes [144].

The amount of iron (59-Fe) in whole animals, their excretions, and body distribution of iron (59-Fe) in blood, liver, spleen, and heart was measured at one, three, and eight weeks following the iron (59-Fe) chelator mixture intragastric administrations and compared to controls, which received the same amount of iron (59-Fe), but no chelator. The mixture contained several times excess chelator over iron. The amount of iron (59-Fe) absorbed was less than $3.5 \%$ of the total iron (59-Fe) administered. The 2-hydroxy-4-methoxypyridine1-oxide (L6) and maltol, which form neutral, lipophilic iron complexes, were found to cause a significant increase in 59-Fe absorption, while hydrophilic chelators including deferoxamine, deferiprone, mimosine, and EDTA caused a significant decrease in iron (59-Fe) absorption by comparison to controls. It was also observed that under the same conditions, 2-hydroxypyridine-1-oxide (L4), 8-hydroxyquinoline, and omadine caused iron precipitation, which was not absorbable. In general, several factors, including chelator concentration, water solubility of the chelator and its iron complex, and food composition, appear to affect iron absorption. The overall in vivo results in mice were in broad agreement with the in vitro results of the RBC and rat inverted intestine experiments, where lipophilic chelators have been shown to increase the transfer of iron across cell membranes and across the gastrointestinal tract, thus increasing iron absorption [25,143,144].

Monitoring of the iron (59-Fe) body distribution in mice following the oral administration of chelator iron mixtures has also shown that most of the iron absorbed from the chelator iron mixtures was detected in RBC and less in the organs, where it was mainly distributed in the liver (50-60\%), compared to the spleen (30-40\%) and heart $(10 \%>)$. Overall, the findings suggested that the iron (59-Fe) absorbed following the oral administration of chelator iron complexes is diverted primarily to the bone marrow and utilised for the production of haemoglobin [144].

Similar results of increased iron (59-Fe) uptake were observed following the intraduodenal administration of the (59-Fe) iron maltol in rats, by comparison to other hydrophilic iron (59-Fe) mixtures with EDTA, gluconate, and fumarate [145]. Dissociation of iron from maltol was suggested following entry in the intestinal wall with each molecule taking a different metabolic pathway [146]. The intravenous administration of an (59-Fe) iron maltol mixture in rats also resulted in the dissociation of iron and maltol, presumably through donation of iron to transferrin and release of maltol [146]. In all rat study cases, iron (59-Fe) uptake was mostly associated with haemoglobin production and less with liver deposition and storage. The increased uptake of iron (59-Fe) in the presence of maltol and its utilisation by the haematopoietic tissues has been observed in both mice and rats, despite the suggested dissociation of iron and maltol, and the kinetic variations in iron uptake following the use of different iron concentrations in the mixture [146].

Prolonged intragastric administration of lipophilic chelators, such as 8-hydroxyquinoline, have been previously shown to cause iron overload in animals by mobilising and transferring iron present in food across the gastrointestinal tract [147,148]. For example, the 18-month administration of 8-hydroxyquinoline in animals caused haemosiderosis initially in the liver 
and spleen, and eventually in the heart, kidneys, adrenal glands, pancreas, testes, and thyroid [147]. It is envisaged that lipophilic natural dietary chelators, such as maltol or synthetic drugs (such as deferasirox) could also increase dietary iron absorption [23,36,42]. In this context, these and other lipophilic chelators could be used for long term administration, promoted as food additives or supplements, and in food fortification for facilitating iron absorption and the prevention of IDA [23].

\subsection{The Effect of Maltol and Maltol Iron Complex on Iron Excretion}

The pharmacological and toxicological properties of the chelators involved in the iron complex formulations are critical parameters for the safety and efficacy used in the selection process for identifying IND for the treatment of IDA [28]. For example, a serious toxic side effect by the chelator, its metabolites, or the iron complex could minimise the prospects of the regulatory approval of the iron complex formulation for clinical use. Similarly, if the iron of the iron complex formulation is absorbed, but rapidly excreted unchanged, or is not utilised by the haematopoietic tissues, then it cannot be considered as a potentially effective IND treatment for IDA [28].

In the case of the maltol iron complex formulation and most of the other lipophilic chelator iron complexes, iron has been shown to be absorbed and utilised by the haematopoietic tissues and also for storage in ferritin [144]. Free unbound maltol dissociated of iron after iron uptake enters the blood stream, metabolised and excreted. In this context, the effect of the dissociated maltol on iron excretion is essential information for determining the iron balance following the administration of the trimaltol iron complex formulations. In the original studies of discovery of the maltol iron complex for potential use in IDA, maltol has also been investigated for possible toxicity and also efficacy in iron removal in mice [25].

No toxicity was observed using maltol at intraperitoneal doses of $500 \mathrm{mg} / \mathrm{kg}$ in mice. In the iron (59-Fe) metabolic studies in mice using intraperitoneal (7 mice) and intragastric (3 mice) administrations of a dose of $250-300 \mathrm{mg} / \mathrm{kg}$, no significant increase in iron excretion was observed with maltol by either route (Figure 7). Under the same conditions using deferiprone intraperitoneally and intragastrically, the increase in iron (59-Fe) excretion was about $270-290 \%$ higher than controls and in the case of deferoxamine about $340 \%$ higher when administered intraperitoneally, but not intragastrically [25].

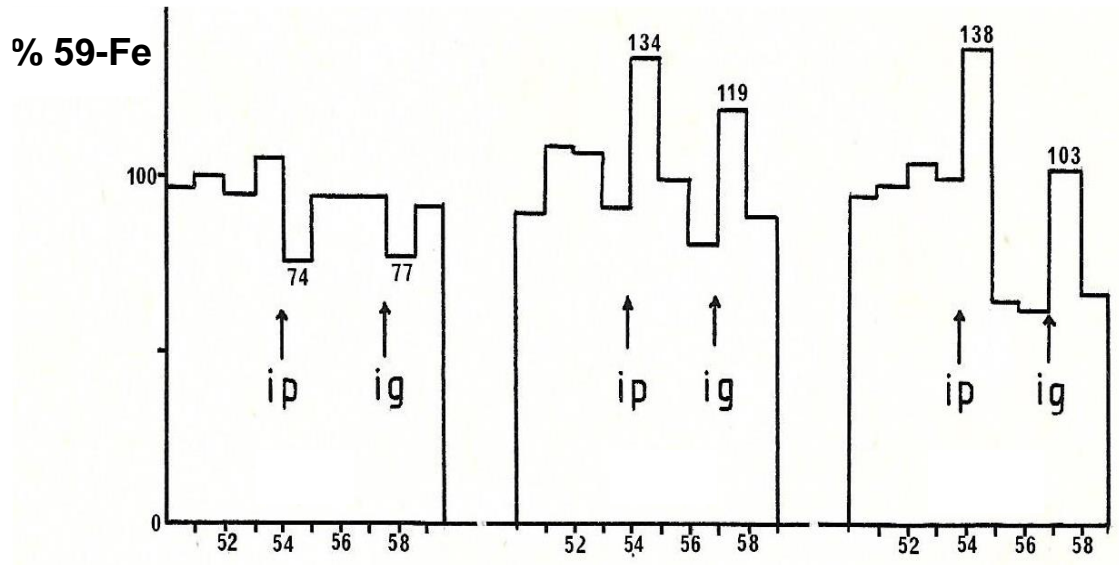

Time / Days

Figure 7. The effect of maltol on daily iron excretion in mice. The profile of iron (59-Fe) excretion in iron loaded, 59-Fe labelled mice following treatment with maltol (250-300 mg/ kg). Maltol was administered in three mice initially intraperitoneally (ip) and after 3 days intragastrically (ig), as indicated by arrows. In each mouse, the mean iron (59-Fe) excretion 3-4 days prior to the recorded values was considered as the background (100\%) excretion of (59-Fe) [25]. 
In contrast to maltol, the lipophilic oral iron chelating drug deferasirox causes both an increase in dietary iron absorption and an increase in iron excretion in iron loaded animals and patients $[42,58,79,149-151]$. However, at the high doses $(20-40 \mathrm{mg} / \mathrm{kg})$ used in iron loaded patients, the level of iron excretion is much higher than the limited amounts of available dietary iron absorption caused by the oral administration of deferasirox [58,79,149-151].

In general, it is anticipated that maltol dissociated from iron following the oral maltol iron mixture formulation administration is not likely to cause increases in iron excretion. Furthermore, the concentration of maltol in the maltol iron formulation dose is very low for dissociated maltol to cause negative iron balance. Similarly, the prospects of toxicity are also very low because of the low dose of maltol by comparison to the dose of the other chelating drugs used in the treatment of iron loaded patients and in other conditions with normal iron stores [152-159].

\section{Factors Affecting the Absorption of Maltol and the Maltol Iron Complex}

Many factors can affect the rate of maltol iron complex absorption and body iron distribution in vivo and in therapeutic responses for different categories of patients. Some of these factors include variations based on individual absorption, distribution, metabolism, excretion, and toxicity (ADMET) response profiles, and pharmacogenomic, proteogenomic, metabolomic, redoxomic, and metallomic factors [28,42,79]. Additional factors related to chelator or chelator metal complex absorption include competition from other metal ions, dietary molecules and drugs, reducing agents, $\mathrm{pH}$ in the gastrointestinal tract, etc. (Table 1) $[28,42,160]$.

In considering the various factors affecting the level of iron absorption following the oral administration of the maltol iron complex mixture, of major importance is the quantity of iron present in the formulation mixture. In addition, dissociated maltol of the iron formulation mixture could also facilitate the absorption of non-haem dietary iron present in the gastrointestinal tract.

Many dietary molecules and medicinal drugs could also interact with maltol and the maltol iron complex and influence the absorption of iron. The presence of dietary molecules with chelating properties such as tannins and phosphates in the gastrointestinal tract will compete with maltol for iron and inhibit its absorption [160-164]. In contrast, lipophilic phytochelators, such as 8-hydroxyquinoline and omadine, could act synergistically and enhance the absorption of iron from the maltol iron complex mixture [147,148]. Similar interactions and influence in the absorption of iron is also anticipated in the presence of drugs with chelating properties. For example deferoxamine, deferiprone, hydroxyurea, penicillamine, bisphosphonates, levodopa, mycophenolate, and tetracycline could interact with the maltol iron complex and inhibit its absorption, whereas deferasirox is anticipated to promote its absorption $[54-56,59,60]$.

Synergistic effects for increasing iron absorption by maltol and the maltol iron complex is anticipated in the presence of reducing agents, such as the chelator antioxidant vitamin ascorbic acid [52]. In contrast, metal ion competitors for binding maltol, such as zinc and copper, could displace iron from the maltol iron complex and decrease gastrointestinal iron absorption [165]. Under normal conditions the inhibition of iron absorption is proportional to the concentration of the competing metal ion [53]. Similar inhibitory effects are expected in the presence of aluminium and other metal ions, which also have high affinity for maltol, other similar chelators, and transferrin [166-168]. In this context, the co-administration of aluminium based antacids or other metal ion mixtures are not recommended for the treatment of IDA with maltol iron complex formulations [53].

All the above anticipated molecular interactions are subject to thermodynamic and kinetic parameters and require further investigations. The formation of ternary complexes of maltol and the maltol iron complex with other chelating molecules, similar to the deferiprone and ascorbate ternary iron complex, is particularly important for assessing the promotion or inhibition of iron absorption [61]. 
Many other factors and conditions from physicochemical molecular changes to clinical variations, due to the underlying conditions in each disease and patient, could also influence the absorption of maltol and the maltol iron complex. For example, the quantity of water, alcohol, and other fluid intake, as well as dietary factors affecting the solubilization of maltol and the maltol iron complex in the formulation could affect iron absorption. Similarly, the $\mathrm{pH}$ of the stomach and intestine, as well as the use of antacids and other drugs and dietary molecules affecting iron transport across the enterocyte, e.g., Nifedipine, which is an L-type calcium channel blocker, could also affect the absorption of iron (Table 1) $[23,36,42,160]$.

Changes in the normal function of the gastrointestinal tract and the haematopoietic tissues is observed in many diseases, including iron metabolic diseases, anaemia of chronic disease in cancer and inflammation, haemoglobinopathies, nephropathy, etc., all of which can affect iron absorption and distribution $[23,57,58,169,170]$. Similar effects are observed in diseases with abnormal organ function, gastrectomy, and other interventions where gastrointestinal tract function is affected, and also in ageing [23,36,42]. In all these cases, the rate of absorption and utilisation of iron from different iron formulations, including the maltol iron complex, is expected to be affected.

\section{Clinical Studies Related to the Efficacy of Iron Maltol in Iron Deficiency Anaemia}

The preclinical and clinical development of the maltol iron complex in animal and clinical studies continued intermittently for many years and by different groups of investigators following its discovery [25]. Many studies are still ongoing for different categories of patients with IDA conditions. In almost all the clinical studies and trials, oral trimaltol iron has been shown to be tolerable and effective, with significant improvements in reversing anaemia and normalising serum iron parameters in different categories of patients with IDA. The most common adverse effect during the clinical studies was mild gastrointestinal intolerance [171,172].

In pharmacokinetic and metabolic randomised phase I study, ferric maltol, and its effect on iron indices has been evaluated in 24 iron deficient patients with inflammatory bowel disease (13 with Crohn's disease and 11 with ulcerative colitis) [173]. The patients received oral ferric maltol 30,60, or $90 \mathrm{mg}$ twice daily during an 8 day period. Rapid absorption was observed following administration, with plasma maltol and maltol glucuronide increasing rapidly at all doses in a dose proportional pattern and reaching maximum plasma concentration 1.0-1.5 h post-dose and declining to baseline after 3-6 h. No maltol accumulation was observed after 7 day dosing. Serum iron and transferrin saturation increased with all doses reaching maximum values at $1.5-3.0 \mathrm{~h}$ post-dose. Similarly, serum ferritin and reticulocyte haemoglobin content increased by the eighth day, with greater improvements at the higher doses [173]. The ferrokinetic, pharmacokinetic and metabolic properties of maltol appear to be very similar to that previously observed with the oral chelating drug deferiprone [91,92].

The efficacy of maltol iron for the treatment of IDA was demonstrated in many other clinical studies and trials. In one study involving 23 patients non-tolerant to ferrous sulphate, maltol iron containing $30 \mathrm{mg}$ iron was taken for 3 months twice daily before breakfast and the evening meal. Nineteen of the 23 patients completed the study and anaemia was fully corrected in 14 of these with mean haemoglobin increasing from 106 to $126 \mathrm{~g} / \mathrm{L}$ and also significant increase in serum ferritin from 8.1 to $17.4 \mu \mathrm{g} / \mathrm{L}$ [174].

In another clinical comparative study, maltol iron administration has been shown in 20 IDA individuals to be both more rapid and total absorption greater than that seen with ferrous sulphate. These results were observed at two different doses of 10 and $60 \mathrm{mg}$ elemental iron tablet formulations [175]. In general, iron from the maltol iron formulation treatment appears to be at least as well absorbed as from the ferrous sulphate formulation, suggesting that ferric maltol was the first ferric iron formulation to be absorbed to a degree equivalent to that of ferrous iron salts [175]. 
In a phase III clinical trial, randomised, double-blind, placebo-controlled study design, which included patients with inflammatory bowel disease, maltol iron administration ( $30 \mathrm{mg}$, twice daily) for up to 12 weeks increased haemoglobin levels of the treated patients in comparison to placebo treated patients. Significant increases of haemoglobin were observed at 4, 6, and 12 weeks after treatment and in two-thirds of the patients' haemoglobin levels normalised at the end of the 12 week period. No toxic side effects were reported and the safety profile was comparable to placebo. Furthermore, the 12-week treatment had no impact on inflammatory bowel disease severity [176]. This study suggested that maltol iron can be used as an alternative to intravenous iron and other iron formulations for the treatment of IDA patients with inflammatory bowel disease [176]. Similar results of the efficacy and safety of maltol iron were obtained in several other studies involving IDA patients with inflammatory bowel disease [170-172,174,176-178].

Several clinical trials in other conditions with IDA, including chronic kidney disease and pulmonary hypertension, have confirmed the high efficacy and low toxicity of maltol iron $[169,171,172,179,180]$. For example, the use of the approved dose of $30 \mathrm{mg}$ twice daily of maltol iron for 12 weeks in 20 pulmonary hypertension patients with IDA caused an increased in the haemoglobin levels from 10.7 to $13.6 \mathrm{~g} / \mathrm{dL}$, in transferrin saturation from $7.5 \%$ to $31.5 \%$, and serum ferritin from 13.1 to $33.6 \mu \mathrm{g} / \mathrm{L}$ [179]. The treatment with maltol iron was well-tolerated over the whole 12-week period.

There are several advantages in selecting trimaltol iron formulation over other iron formulations for the treatment of IDA. It is generally effective, safe and more selective in iron delivery than other formulations because of its lipophilicity, physiochemical, pharmacological, and other properties $[25,78,79,171,172,174]$. The selectivity for iron delivery by maltol formulations decreases the toxicity associated with the excess, non-absorbable iron observed with other iron formulations. Furthermore, the high efficacy and low toxicity of maltol iron formulations could benefit many patients experiencing complications and toxicity with intravenous iron, ferrous sulphate and other iron formulations [181-186].

In considering individual patient variations on responses, such as ease of administration, low toxicity and timing of the normalisation of haemoglobin, maltol iron formulations may also appear to have further advantages over the other iron formulations. The cost of maltol iron and worldwide accessibility to patients is another major issue affecting global health strategies, especially since the vast majority of IDA patients live in developing countries. However, the cost of maltol and iron are negligible and many other maltol iron formulations can be prepared and considered as off-patent or generic pharmaceuticals $[69,79]$. Overall, maltol iron has the prospects of becoming the first choice for worldwide treatment of patients with IDA.

\section{Potential Applications of Maltol and Maltol Metal Complexes in Medicine}

Despite that the discovery and characterisation of maltol and other novel KHP chelators and their metal complexes, as well as their potential for clinical uses was identified about 40 years ago, the progress regarding their pharmaceutical development was very slow $[25,69]$. In the case of maltol, the pharmaceutical development process could have been rapid and inexpensive, considering that it was a widely available natural product and food component, which has been used for more than 50 years.

There are many prospects for the use of iron and other metal complexes of maltol. One new therapeutic approach is the potential use of maltol in food and drink fortification, which may be considered as an additional method for treating IDA, considering that maltol can facilitate the absorption of non-haem dietary iron present in the gastrointestinal tract. The slow increase of dietary iron uptake over long-term periods using food products fortified with maltol may benefit millions of IDA patients worldwide and especially in developing countries where IDA is a major health problem. This approach is anticipated to be less toxic than the administration of established iron formulations where most of the iron is not absorbed causing toxicity in the gastrointestinal tract (Table 3) [12-14,184-186]. 
Maltol and other lipophilic chelators, as well as their metal complexes, could be used for many other applications and areas of medicine [28,53,187-196]. Some of these applications include the treatment of other essential metal deficiency or related diseases, such as diabetes, delivery of redox active metal complexes against cancer cells and delivery of xenobiotic metals to disrupt essential metal, e.g., iron pathways in cancer, diagnostic metal delivery in diseases, including inflammation and cancer, radiolabelling of cells using metal radiotracers, and finally, theranostic metal delivery in different diseases [28,53,187-196].

The ability of maltol to bind different metal ions and to form lipophilic metal complexes, its interaction with transferrin and metal transfer ability intracellularly, as well as its low toxicity make it an ideal candidate for many clinical applications in addition to its iron complex role for the treatment of IDA $[11,28,88]$. The affinity of maltol for many other metal ions in addition to iron such as copper, zinc, aluminium, gallium, indium, gadolinium, ruthenium, chromium, and vanadium is similar to (but lower than) that observed with transferrin and deferiprone [88,187-197]. Within this context, the theranostic and diagnostic fields associated with the xenobiotic metal complexes of maltol involve many diseases and applications which are continuously expanding and evaluated [192-197].

One major medical application of maltol is related to the trimaltol gallium complex (gallium maltolate), which is one of the most developed maltol metal complexes that have reached the stage of clinical trials and veterinarian use mainly for anticancer and antimicrobial activity [197-210]. The maltol gallium complex of maltol 3:1 gallium stoichiometry is neutral, similar to the trimaltol iron complex but is slightly more lipophilic, with the n-octanol/water partition coefficient of 0.40 versus 0.32 of the trimaltol iron complex.

The basic anticancer and antimicrobial targeting of maltol gallium is the delivery of gallium to cells which mimics iron and affects iron-related metabolic pathways. In this context, the antimicrobial activity of trimaltol gallium is thought to be based on the substitution of iron by gallium causing the deprivation of iron, which is essential for the rapid growth of pathogenic microbes [130-133,203-210]. The anticancer activity of trimaltol gallium is thought to be based on the delivery of gallium to transferrin causing reduction of cancer cell acquisition of iron and growth reduction through the slow turnover of the iron dependent enzyme ribonucleotide reductase leading to the inhibition of DNA synthesis [28,88,188,196-202]. In particular, cancer types, such as breast, prostate, bladder, and leukaemia with abundance of transferrin receptors and upregulated production of ribonucleotide reductase render such tumour cells susceptible to the cytotoxicity of gallium [28,88,188,196-202,211].

Another major, rapidly expanding area of the application of maltol and other chelators in medicine is in the diagnostic and theranostic fields [28]. The design and targeted use of different chelating agents, which form metal complexes of variable physicochemical properties, appear to affect the bodily distribution of specific metal radiotracers and are increasingly applied for the diagnosis, as well as progress tracking of different diseases [28,212,213]. Similar targeted chelator metal complexes have been identified for the theranostic application of radiotracer metals in inflammation, cancer, and other diseases $[28,212,213]$. For example, it has been shown that, in the case of trimaltol gallium (67-Ga) complex in hepatocellular carcinoma patients, the cancer was highly gallium-avid in a (67-Ga) diagnostic scan and was treated with oral trimaltol gallium complex at 4 doses of $1.5 \mathrm{~g}$ /day for four weeks. Significant improvements of cancer indices were observed and necrosis of the tumour has been shown by CT scans at eight weeks [202].

There are many other areas of potential investigations and applications in medicine involving maltol and maltol metal complexes. In each case, specific conditions are applied and appropriate protocols need to be designed. For example, intravenous trimaltol iron complex formulations may have to be designed to benefit IDA cancer and other categories of patients [28,214-216]. Mixed chelator iron complexes of maltol and ascorbate may also be designed for increasing the efficacy of gastrointestinal iron uptake for the treatment of IDA. Similarly, the use of other metal complexes may also result in the improvement 
of diagnostic and theranostic applications, as well as in synergistic effects with drugs or proteins in the treatment of different diseases [28,52,61,217-220].

\section{Conclusions}

Iron deficiency anaemia affects billions of patients worldwide, including children, pregnant women, vegetarians, malnourished individuals, as well as patients with cancer, inflammatory bowel disease, chronic kidney disease, and many other diseases. There are many ferric and ferrous iron formulations available for the treatment of IDA, but most of these are not sufficiently effective and cause toxic side effects, mainly because of the excess iron administration.

The identification and characterisation of the in vitro and in vivo properties of maltol and the trimaltol iron complex has instigated the clinical investigations and development of new pharmaceuticals for use in iron deficiency and several other areas of medicine. In particular, as a result of the clinical approval of the trimaltol iron complex significant therapeutic improvements have been observed in different categories of patients with IDA, increasing the prospects of introducing more effective and less toxic treatments for millions of patients worldwide.

The specificity of the alpha-keto hydroxy binding site of the KHP chelators for iron, the neutral charge, and the lipophilicity of maltol and its iron complex are some of the molecular characteristics that contributed to the development of this new class of pharmaceuticals. Similar molecular characteristics have been observed in 2-hydroxy-4-methoxypyridine-1oxide (L6), tropolone, and 8-hydroxyquinoline, which have also been shown to increase iron absorption in animals, and the same-or their analogues-may also be developed for the treatment of IDA.

The development of maltol and other naturally occurring lipophilic iron chelators as nutraceuticals, and in food fortification, may increase the prospects of facilitating the treatment of IDA in many categories of patients, including malnourished and poor patients in developing countries.

Several other possible clinical applications of metal maltol or other lipophilic metal complexes are currently developed, such as metal radiotracers in diagnostic medicine, theranostic formulations, and anticancer formulations. In particular, the clinical evaluation of trimaltol gallium in cancer patients increases the prospects of development of a new class of therapeutics in cancer, infectious diseases, and other diseases.

Further studies are required for identifying the mode of action and effects of maltol iron and other lipophilic iron complexes on iron metabolism at the molecular and subcellular levels, and other levels. In particular, the interactions of maltol and maltol iron complex with proteins of iron metabolism are very important in the turnover and inhibition/activation of enzymes, such as ferroportin and hepcidin involved in metabolic pathways associated with iron absorption, and other normal bodily functions. Similarly, further studies are required for the evaluation of the interactions among maltol xenobiotic metal complexes with iron metabolic pathways, and other pathways affecting their metabolism, toxicity, and therapeutic actions.

Funding: This research received no external funding.

Institutional Review Board Statement: Not applicable.

Informed Consent Statement: Not applicable.

Data Availability Statement: Not applicable.

Acknowledgments: + Dedication: The paper is dedicated to Phedias Soteriou, who played a leading role in the development of iron chelation therapy and recently passed away.

Conflicts of Interest: George J. Kontoghiorghes, the inventor of trimaltol iron (ferric maltol) and the other authors declare no conflict of interest. The authors have no commercial associations including consultancies, stock ownership, equity interest, patent/licensing arrangement etc. that might pose a conflict of interest in connection with the submitted article. 


$\begin{array}{ll}\text { Abbreviations } & \\ \text { 2,4-Dihydroxypyridine-1-oxide } & \text { (L3) } \\ \text { 2-Hydroxypyridine-1-oxide } & \text { (L4) } \\ \text { 2-Hydroxy-4- methoxypyridine-1-oxide } & \text { (L6) } \\ \text { Diferric transferrin } & \text { (Fe-T-Fe) } \\ \text { Divalent metal transported protein } & \text { (DMT1) } \\ \text { Ethylenediaminetetraacetic acid } & \text { (EDTA) } \\ \text { Optical density } & \text { (OD) } \\ \text { Hydroxyeicosatetraenoic acid } & \text { (HETE) } \\ \text { Hydroperoxyeicosatetraenoic acid } & \text { (HPETE) } \\ \text { Investigational new drugs } & \text { (IND) } \\ \text { Iron deficiency anaemia } & \text { (IDA) } \\ \text { Red blood cells } & \text { (RBC) }\end{array}$

\section{References}

1. Katsarou, A.; Pantopoulos, K. Basics and principles of cellular and systemic iron homeostasis. Mol. Aspects Med. 2020, 75, 100866. [CrossRef] [PubMed]

2. Gozzelino, R.; Arosio, P. Iron Homeostasis in Health and Disease. Int. J. Mol. Sci. 2016, 17, 130. [CrossRef] [PubMed]

3. Cairo, G.; Bernuzzi, F.; Recalcati, S.A. A precious metal: Iron, an essential nutrient for all cells. Genes Nutr. 2006, 1, 25-39. [CrossRef] [PubMed]

4. Andrews, N.C. Disorders of iron metabolism. N. Engl. J. Med. 1999, 341, 1986-1995, Erratum in 2000, 342, 364. [CrossRef] [PubMed]

5. Prasad, A.S. Zinc: An overview. Nutrition 1995, 11 (Suppl. S1), 93-99.

6. Coleman, J.E. Zinc proteins: Enzymes, storage proteins, transcription factors, and replication proteins. Annu. Rev. Biochem. 1992, 61, 897-946. [CrossRef]

7. Prasad, A.S. Zinc deficiency. BMJ 2003, 326, 409-410. [CrossRef]

8. Daniel, K.G.; Harbach, R.H.; Guida, W.C.; Dou, Q.P. Copper storage diseases: Menkes, Wilsons, and cancer. Front. Biosci. 2004, 9 , 2652-2662. [CrossRef]

9. Baldari, S.; Di Rocco, G.; Toietta, G. Current Biomedical Use of Copper Chelation Therapy. Int. J. Mol. Sci. 2020, 21, 1069. [CrossRef]

10. Balsano, C.; Porcu, C.; Sideri, S. Is copper a new target to counteract the progression of chronic diseases? Metallomics 2018, 10, 1712-1722. [CrossRef]

11. Kontoghiorghe, G.J.; Kontoghiorghe, C.N. Iron and Chelation in Biochemistry and Medicine: New Approaches to Controlling Iron Metabolism and Treating Related Diseases. Cells 2020, 9, 1456. [CrossRef]

12. McLean, E.; Cogswell, M.; Egli, I.; Wojdyla, D.; De Benoist, B. Worldwide Prevalence of Anaemia, WHO Vitamin and Mineral Nutrition Information System, 1993-2005. Public Health Nutr. 2009, 12, 444-454. [CrossRef]

13. Pasricha, S.R.; Tye-Din, J.; Muckenthaler, M.U.; Swinkels, D.W. Iron deficiency. Lancet 2021, 397, 233-248. [CrossRef] [PubMed]

14. Tardy, A.L.; Pouteau, E.; Marquez, D.; Yilmaz, C.; Scholey, A. Vitamins and Minerals for Energy, Fatigue and Cognition: A Narrative Review of the Biochemical and Clinical Evidence. Nutrients 2020, 12, 228. [CrossRef]

15. Moustarah, F.; Mohiuddin, S.S. Dietary iron. In StatPearls; StatPearls Publishing: Treasure Island, FL, USA, 2020.

16. Pantopoulos, K. TfR2 links iron metabolism and erythropoiesis. Blood 2015, 125, 1055-1056. [CrossRef]

17. Makey, D.G.; Seal, U.S. The detection of four molecular forms of human transferrin during the iron binding process. Biochim. Biophys. Acta 1976, 453, 250-256. [CrossRef]

18. Gomme, P.T.; McCann, K.B.; Bertolini, J. Transferrin: Structure, function and potential therapeutic actions. Drug Discov. Today 2005, 10, 267-273. [CrossRef]

19. Sargent, P.J.; Farnaud, S.; Evans, R.W. Structure/function overview of proteins involved in iron storage and transport. Curr. Med. Chem. 2005, 12, 2683-2693. [CrossRef]

20. Mehlenbacher, M.; Poli, M.; Arosio, P.; Santambrogio, P.; Levi, S.; Chasteen, N.D.; Bou-Abdallah, F. Iron Oxidation and Core Formation in Recombinant Heteropolymeric Human Ferritins. Biochemistry 2017, 56, 3900-3912. [CrossRef]

21. Theil, E.C. Ferritin: The protein nanocage and iron biomineral in health and in disease. Inorg. Chem. 2013, 52, 12223-12233. [CrossRef]

22. Iancu, T.C. Ferritin and hemosiderin in pathological tissues. Electron. Microsc Rev. 1992, 5, 209-229. [CrossRef]

23. Kontoghiorghes, G.J.; Kolnagou, A. Molecular factors and mechanisms affecting iron and other metal excretion or absorption in health and disease. The role of natural and synthetic chelators. Curr. Med. Chem. 2005, 12, 2695-2709. [CrossRef]

24. Anderson, F.W.; Hiller, M.C. (Eds.) Development of Iron Chelators for Clinical Use; DHEW Publication No. (NIH) 77-994; DHEW Publication: Bethesda, MD, USA, 1975; pp. 1-275. 
25. Kontoghiorghes, G.J. The Design of Orally Active Iron Chelators for the Treatment of Thalassaemia. Ph.D. Thesis, University of Essex, Colchester, UK, 1982; pp. 1-243, British Library. Microfilm No D66194/86. Available online: https://www.pri.ac.cy/files/ KGJ_thesis_1982.pdf (accessed on 20 May 2021).

26. Kawabata, H. Transferrin and transferrin receptors update. Free Radic. Biol. Med. 2019, 133, 46-54. [CrossRef]

27. Wang, B.; Timilsena, Y.P.; Blanch, E.; Adhikari, B. Lactoferrin: Structure, function, denaturation and digestion. Crit. Rev. Food Sci. Nutr. 2019, 59, 580-596. [CrossRef]

28. Kontoghiorghes, G.J. Advances on Chelation and Chelator Metal Complexes in Medicine. Int. J. Mol. Sci. 2020, $21,2499$. [CrossRef]

29. Kobayashi, M.; Suhara, T.; Baba, Y.; Kawasaki, N.K.; Higa, J.K.; Matsui, T. Pathological Roles of Iron in Cardiovascular Disease. Curr. Drug Targets 2018, 19, 1068-1076. [CrossRef]

30. Wessells, K.R.; Young, R.R.; Ferguson, E.L.; Ouédraogo, C.T.; Faye, M.T.; Hess, S.Y. Assessment of Dietary Intake and Nutrient Gaps, and Development of Food-Based Recommendations, Among Pregnant and Lactating Women in Zinder, Niger: An Optifood Linear Programming Analysis. Nutrients 2019, 11, 72. [CrossRef]

31. Zhang, C.; Rawal, S. Dietary Iron Intake, Iron Status, and Gestational Diabetes. Am. J. Clin. Nutr. 2017, 106, 1672-1680. [CrossRef]

32. Man, C.D.; Maideen, S.F.K.; Rashid, A. Knowledge, Attitude and Practice towards Dietary Iron among Patients with Thalassemia and Their Caregivers in Peninsular Malaysia. Med. J. Malays 2019, 74, 365-371.

33. Ganz, T. Anemia of Inflammation. N. Engl. J. Med. 2019, 381, 1148-1157. [CrossRef] [PubMed]

34. Tolkien, Z.; Stecher, L.; Mander, A.P.; Pereira, D.I.; Powell, J.J. Ferrous sulfate supplementation causes significant gastrointestinal side-effects in adults: A systematic review and meta-analysis. PLoS ONE 2015, 10, e0117383, PMCID:PMC4336293. [CrossRef] [PubMed]

35. Bouvard, V.; Loomis, D.; Guyton, K.Z.; Grosse, Y.; El Ghissassi, F.; Benbrahim-Tallaa, L.; Guha, N.; Mattock, H.; Straif, K.; Stewart, B.W.; et al. Carcinogenicity of Consumption of Red and Processed Meat. Lancet Oncol. 2015, 16, 1599-1600. [CrossRef]

36. Kontoghiorghe, C.N.; Kolnagou, A.; Kontoghiorghes, G.J. Dietary and Pharmacological Factors Affecting Iron Absorption in Mice and Man (Comment for a Letter to the Editor). Haematologica 2016, 101, 120-121. [CrossRef] [PubMed]

37. Sim, M.; Garvican-Lewis, L.A.; Cox, G.R.; Govus, A.; McKay, A.K.A.; Stellingwerff, T.; Peeling, P. Iron considerations for the athlete: A narrative review. Eur. J. Appl. Physiol. 2019, 119, 1463-1478. [CrossRef] [PubMed]

38. Salvin, H.E.; Pasricha, S.R.; Marks, D.C.; Speedy, J. Iron deficiency in blood donors: A national cross-sectional study. Transfusion 2014, 54, 2434-2444. [CrossRef] [PubMed]

39. Mantadakis, E.; Chatzimichael, E.; Zikidou, P. Iron Deficiency Anemia in Children Residing in High and Low-Income Countries: Risk Factors, Prevention, Diagnosis and Therapy. Mediterr. J. Hematol. Infect. Dis. 2020, 12, e2020041, PMCID:PMC7340216. [CrossRef] [PubMed]

40. Grover, K.; Kumar, T.; Doda, A.; Bhutani, R.; Yadav, S.; Kaushal, P.; Kapoor, R.; Sharma, S. Prevalence of anaemia and its association with dietary habits among pregnant women in the urban area of Haryana. J. Fam. Med. Prim. Care 2020, 9, 783-787, PMCID:PMC7114061. [CrossRef] [PubMed]

41. Savva, S.C.; Kafatos, A. Is red meat required for the prevention of iron deficiency among children and adolescents? Curr. Pediatr. Rev. 2014, 10, 177-183. [CrossRef] [PubMed]

42. Kontoghiorghes, G.J.; Spyrou, A.; Kolnagou, A. Iron chelation therapy in hereditary hemochromatosis and thalassemia intermedia: Regulatory and non regulatory mechanisms of increased iron absorption. Hemoglobin 2010, 34, 251-264. [CrossRef] [PubMed]

43. Girelli, D.; Nemeth, E.; Swinkels, D.W. Hepcidin in the diagnosis of iron disorders. Blood 2016, 127, 2809-2813, PMCID:PMC4956612. [CrossRef] [PubMed]

44. Aschemeyer, S.; Qiao, B.; Stefanova, D.; Valore, E.V.; Sek, A.C.; Alex Ruwe, T.; Vieth, K.R.; Jung, G.; Casu, C.; Rivella, S.; et al. Structure-function analysis of ferroportin defines the binding site and an alternative mechanism of action of hepcidin. Blood 2018, 131, 899-910, PMCID:PMC5824336. [CrossRef] [PubMed]

45. Powers, A.S.; Gonen, S.; Schneider, S.; Arvedson, T.; Dror, R.O.; Cheng, Y.; Manglik, A. Structure of hepcidin-bound ferroportin reveals iron homeostatic mechanisms. Nature 2020, 586, 807-811. [CrossRef] [PubMed]

46. Zhang, D.L.; Ghosh, M.C.; Ollivierre, H.; Li, Y.; Rouault, T.A. Ferroportin deficiency in erythroid cells causes serum iron deficiency and promotes hemolysis due to oxidative stress. Blood 2018, 132, 2078-2087, PMCID:PMC6236465. [CrossRef] [PubMed]

47. Drakesmith, H.; Nemeth, E.; Ganz, T. Ironing out Ferroportin. Cell Metab. 2015, 22, 777-787, PMCID:PMC4635047. [CrossRef] [PubMed]

48. Pietrangelo, A. Ferroportin disease: Pathogenesis, diagnosis and treatment. Haematologica 2017, 102, 1972-1984, PMCID:PMC5709096. [CrossRef] [PubMed]

49. Byrnes, V.; Barrett, S.; Ryan, E.; Kelleher, T.; O'Keane, C.; Coughlan, B.; Crowe, J. Increased duodenal DMT-1 expression and unchanged HFE mRNA levels in HFE-associated hereditary hemochromatosis and iron deficiency. Blood Cells Mol. Dis. 2002, 29, 251-260. [CrossRef] [PubMed]

50. Pantopoulos, K. Function of the hemochromatosis protein HFE: Lessons from animal models. World J. Gastroenterol. 2008, 14, 6893-6901. [CrossRef]

51. Gombart, A.F.; Pierre, A.; Maggini, S. A Review of Micronutrients and the Immune System—Working in Harmony to Reduce the Risk of Infection. Nutrients 2020, 12, 236. [CrossRef] 
52. Kontoghiorghes, G.J.; Kolnagou, A.; Kontoghiorghe, C.N.; Mourouzidis, L.; Timoshnikov, V.A.; Polyakov, N.E. Trying to Solve the Puzzle of the Interaction of Ascorbic Acid and Iron: Redox, Chelation and Therapeutic Implications. Medicines 2020, 7, 45. [CrossRef]

53. Sheppard, L.N.; Kontoghiorghes, G.J. Competition between deferiprone, desferrioxamine and other chelators for iron and the effect of other metals. Drug Res. 1993, 43, 659-663. [PubMed]

54. Dresow, B.; Fischer, R.; Nielsen, P.; Gabbe, E.E.; Piga, A. Effect of oral iron chelator L1 on iron absorption in man. Ann. N. Y. Acad. Sci. 1998, 850, 466-468. [CrossRef] [PubMed]

55. Jackson, T.W.; Ling, L.J.; Washington, V. The effect of oral deferoxamine on iron absorption in humans. J. Toxicol. Clin. Toxicol. 1995, 33, 325-329. [CrossRef] [PubMed]

56. Gomez, H.F.; McClafferty, H.H.; Flory, D.; Brent, J.; Dart, R.C. Prevention of gastrointestinal iron absorption by chelation from an orally administered premixed deferoxamine/charcoal slurry. Ann. Emerg Med. 1997, 30, 587-592. [CrossRef] [PubMed]

57. Kontoghiorghes, G.J.; Eracleous, E.; Economides, C.; Kolnagou, A. Advances in iron overload therapies. Prospects for effective use of deferiprone (L1), deferoxamine, the new experimental chelators ICL670, GT56-252, L1NAll and their combination. Curr. Med. Chem. 2005, 12, 2663-2681. [CrossRef]

58. Kontoghiorghe, C.N.; Kontoghiorghes, G.J. Efficacy and safety of iron-chelation therapy with deferoxamine, deferiprone, and deferasirox for the treatment of iron-loaded patients with non-transfusion-dependent thalassemia syndromes. Drug Des. Devel. Ther. 2016, 10, 465-481. [CrossRef]

59. Djaldetti, M.; Fishman, P.; Notti, I.; Bessler, H. The effect of tetracycline administration on iron absorption in mice. Biomedicine 1981, 35, 150-152.

60. Konstantinou, E.; Pashalidis, I.; Kolnagou, A.; Kontoghiorghes, G.J. Interactions of hydroxycarbamide (hydroxyurea) with iron and copper: Implications on toxicity and therapeutic strategies. Hemoglobin 2011, 35, 237-246. [CrossRef]

61. Timoshnikov, V.A.; Kobzeva, T.V.; Polyakov, N.E.; Kontoghiorghes, G.J. Redox Interactions of Vitamin C and Iron: Inhibition of the Pro-Oxidant Activity by Deferiprone. Int. J. Mol. Sci. 2020, 21, 3967. [CrossRef]

62. Senba, M.; Nakamura, T.; Itakura, H. Relationships among iron accumulation, cirrhosis, and hepatitis B virus infection in Bantu siderosis. Ann. Soc. Belg. Med. Trop. 1989, 69, 77-78.

63. Robertson, A.; Tenenbein, M. Hepatotoxicity in acute iron poisoning. Hum. Exp. Toxicol. 2005, 24, 559-562. [CrossRef]

64. Baranwal, A.K.; Singhi, S.C. Acute iron poisoning: Management guidelines. Indian Pediatr. 2003, 40, 534-540.

65. Lucarelli, G.; Angelucci, E.; Giardini, C.; Baronciani, D.; Galimberti, M.; Polchi, P.; Bartolucci, M.; Muretto, P.; Albertini, F. Fate of iron stores in thalassaemia after bone-marrow transplantation. Lancet 1993, 342, 1388-1391. [CrossRef] [PubMed]

66. Lucarelli, G.; Galimberti, M.; Polchi, P.; Angelucci, E.; Baronciani, D.; Giardini, C.; Andreani, M.; Agostinelli, F.; Albertini, F.; Clift, R.A. Marrow transplantation in patients with thalassemia responsive to iron chelation therapy. N. Engl. J. Med. 1993, 329, 840-844. [CrossRef] [PubMed]

67. Lopez, A.; Cacoub, P.; Macdougall, I.C.; Peyrin-Biroulet, L. Iron deficiency anaemia. Lancet 2016, 387, 907-916. [CrossRef] [PubMed]

68. Kang, W.; Barad, A.; Clark, A.G.; Wang, Y.; Lin, X.; Gu, Z.; O’Brien, K.O. Ethnic Differences in Iron Status. Adv. Nutr. 2021, nmab035. [CrossRef] [PubMed]

69. Kontoghiorghe, C.N.; Andreou, N.; Constantinou, K.; Kontoghiorghes, G.J. World health dilemmas: Orphan and rare diseases, orphan drugs and orphan patients. World J. Methodol. 2014, 4, 163-188, PMCID:PMC4202455. [CrossRef] [PubMed]

70. Rao, C.P.; Geetha, K.; Raghavan, M.S.S.; Sreedhara, A.; Tokunaga, K.; Yamaguchi, T.; Jadhav, V.; Ganesh, K.N.; Krishnamoorthy, T.; Ramaiah, K.V.A.; et al. Transition Metal Saccharide Chemistry and Biology: Syntheses, Characterization, Solution Stability and Putative Bio-Relevant Studies of Iron-Saccharide Complexes. Inorg. Chim. Acta 2000, 297, 373-382. [CrossRef]

71. Chandra, J. Treating Iron Deficiency Anemia. Indian J. Pediatr. 2019, 86, 1085-1086. [CrossRef]

72. Pachuta Węgier, L.; Kubiak, M.; Liebert, A.; Clavel, T.; Montagne, A.; Stennevin, A.; Roye, S.; Boudribila, A. Ferrous Sulfate Oral Solution in Young Children with Iron Deficiency Anemia. Pediatr. Int. 2020. [CrossRef]

73. Valenzuela, C.; Olivares, M.; Brito, A.; Hamilton-West, C.; Pizarro, F. Is a $40 \%$ Absorption of Iron from a Ferrous ascorbate Reference Dose Appropriate to Assess Iron Absorption Independent of Iron Status? Biol. Trace Elem. Res. 2013, 155, 322-326. [CrossRef]

74. Patil, P.; Geevarghese, P.; Khaire, P.; Joshi, T.; Suryawanshi, A.; Mundada, S.; Pawar, S.; Farookh, A. Comparison of Therapeutic Efficacy of Ferrous Ascorbate and Iron Polymaltose Complex in Iron Deficiency Anemia in Children: A Randomized Controlled Trial. Indian J. Pediatr. 2019, 86, 1112-1117. [CrossRef]

75. Tarng, D.C.; Huang, T.P.; Wei, Y.H. Erythropoietin and Iron: The Role of Ascorbic Acid. Nephrol. Dial. Transplant. 2001, 16, 35-39. [CrossRef]

76. Sourabh, S.; Bhatia, P.; Jain, R. Favourable Improvement in Haematological Parameters in Response to Oral Iron and Vitamin C Combination in Children with Iron Refractory Iron Deficiency Anemia (IRIDA) Phenotype. Blood Cells Mol. Dis. 2019, 75, 26-29. [CrossRef]

77. Scheers, N.; Sandberg, A.S. Iron Transport through Ferroportin Is Induced by Intracellular Ascorbate and Involves IRP2 and HIF2 $\alpha$. Nutrients 2014, 3, 249-260. [CrossRef]

78. Kontoghiorghes, G.J.; Barr, J.; Nortey, P.; Sheppard, L. Selection of a new generation of orally active alpha-ketohydroxypyridine iron chelators intended for use in the treatment of iron overload. Am. J. Hematol. 1993, 42, 340-349. [CrossRef] [PubMed] 
79. Kontoghiorghe, C.N.; Kontoghiorghes, G.J. New developments and controversies in iron metabolism and iron chelation therapy. World J. Methodol. 2016, 6, 1-19, PMCID:PMC4804243. [CrossRef] [PubMed]

80. Kontoghiorghe, C.N.; Kolnagou, A.; Kontoghiorghes, G.J. Phytochelators Intended for Clinical Use in Iron Overload, Other Diseases of Iron Imbalance and Free Radical Pathology. Molecules 2015, 20, 20841-20872. [CrossRef] [PubMed]

81. Rennhard, H.H. The metabolism of ethyl maltol and maltol in the dog. J. Agric. Food Chem. 1971, 19, 152-154. [CrossRef] [PubMed]

82. Arosio, P.; Elia, L.; Poli, M. Ferritin, cellular iron storage and regulation. IUBMB Life 2017, 69, 414-422. [CrossRef] [PubMed]

83. Saito, H. Storage Iron Turnover from a New Perspective. Acta Haematol. 2019, 141, 201-208. [CrossRef]

84. La, A.; Nguyen, T.; Tran, K.; Sauble, E.; Tu, D.; Gonzalez, A.; Kidane, T.Z.; Soriano, C.; Morgan, J.; Doan, M.; et al. Mobilization of iron from ferritin: New steps and details. Metallomics 2018, 10, 154-168. [CrossRef]

85. Wang, W.; Knovich, M.A.; Coffman, L.G.; Torti, F.M.; Torti, S.V. Serum ferritin: Past, present and future. Biochim. Biophys. Acta 2010, 1800, 760-769. [CrossRef]

86. Kontoghiorghes, G.J. The study of iron mobilisation from transferrin using $\alpha$-ketohydroxy heteroaromatic chelators. Biochim. Biophys. Acta 1986, 869, 141-146. [CrossRef]

87. Kontoghiorghes, G.J. Iron mobilisation from lactoferrin by chelators at physiological pH. Biochim. Biophys. Acta 1986, 882, 267-270. [CrossRef]

88. Kontoghiorghe, C.N.; Kolnagou, A.; Kontoghiorghes, G.J. Potential clinical applications of chelating drugs in diseases targeting transferrin-bound iron and other metals. Expert Opin. Investig. Drugs 2013, 22, 591-618. [CrossRef]

89. Levina, A.; Lay, P.A. Transferrin Cycle and Clinical Roles of Citrate and Ascorbate in Improved Iron Metabolism. ACS Chem. Biol. 2019, 14, 893-900. [CrossRef]

90. Pratt, R.; Handelman, G.J.; Edwards, T.E.; Gupta, A. Ferric pyrophosphate citrate: Interactions with transferrin. Biometals 2018, 31, 1081-1089. [CrossRef]

91. Evans, R.W.; Sharma, M.; Ogwang, W.; Patel, K.J.; Bartlett, A.N.; Kontoghiorghes, G.J. The effect of $\alpha$-ketohydroxypyridine chelators on transferrin saturation in vitro and in vivo. Drugs Today 1992, 28, 9-23.

92. Kontoghiorghes, G.J.; Goddard, J.G.; Bartlett, A.N.; Sheppard, L. Pharmacokinetic studies in humans with the oral iron chelator 1,2-dimethyl-3-hydroxypyrid-4-one. Clin. Pharmacol. Ther. 1990, 48, 255-261. [CrossRef]

93. Vreugdenhil, G.; Kontoghiorghes, G.J.; Van Eijk, H.G.; Swaak, A.J.G. Impaired erythropoietin responsiveness to the anemia in rheumatoid arthritis. A possible inverse relationship with iron stores and effects of the oral iron chelator 1,2-dimethyl-3hydroxypyrid-4-one. Clin. Exp. Rheumatol. 1991, 9, 35-40.

94. Vreughtenhil, G.; Kontoghiorghes, G.J.; Van Eijk, H.G.; Swaak, A.J.G. Efficacy and safety of the oral chelator L1 in anaemic rheumadoit arthritis patients. Lancet 1989, II, 1398-1399. [CrossRef]

95. Kontoghiorghes, G.J. Iron mobilization from transferrin and non-transferrin bound iron by deferiprone. Implications in the treatment of thalassaemia, anaemia of chronic disease, cancer and other conditions. Hemoglobin 2006, 30, 183-200. [CrossRef] [PubMed]

96. Kontoghiorghes, G.J. Iron mobilization from ferritin using alpha-oxohydroxy heteroaromatic chelators. Biochem. J. 1986, 233, 299-302. [CrossRef] [PubMed]

97. Kontoghiorghes, G.J.; Chambers, S.; Hoffbrand, A.V. Comparative study of iron mobilization from haemosiderin, ferritin and iron(III) precipitates by chelators. Biochem. J. 1987, 241, 87-92. [CrossRef]

98. Kontoghiorghes, G.J. Decreased solubilisation of ferritin iron and fresh iron (III) precipitate following repeated chelator treatments. Inorg. Chim. Acta 1987, 138, 36-40. [CrossRef]

99. Mostert, L.J.; Van Dorst, J.A.L.M.; Koster, J.F.; Van Eijk, H.G.; Kontoghiorghes, G.J. Free radical and cytotoxic effects of chelators and their iron complexes in the hepatocyte. Free Rad. Res. Comms. 1987, 3, 379-388. [CrossRef]

100. Jeremy, J.Y.; Gill, J.; Prior, T.; Sifaksi, G.; Barradas, M.A.; Kontoghiorghes, G.J. Inhibition of cycloxygenase and lipoxygenase activity by iron chelators: Possible use in the treatment of eicosanoid-related disorders. Drugs Today 1992, 28 (Suppl. SA), 35-43.

101. Jeremy, J.Y.; Kontoghiorghes, G.J.; Hoffbrand, A.V.; Dandona, P. The iron chelators desferrioxamine and 1-alkyl-2-methyl-3hydroxypyrid-4-ones inhibit vascular prostacyclin synthesis in vitro. Biochem. J. 1988, 254, 239-244. [CrossRef]

102. Barradas, M.A.; Jeremy, J.Y.; Kontoghiorghes, G.J.; Mikhailidis, D.P.; Hoffbrand, A.V.; Dandona, P. Iron chelators inhibit human platelet aggregation, thromboxane A2 synthesis and lipoxygenase activity. FEBS Lett. 1989, 245, 105-109. [CrossRef] [PubMed]

103. Denisov, E.T.; Afanas'ev, I.B. Oxidation and Antioxidants in Organic Chemistry and Biology; CRC Press: Boca Raton, FL, USA; Taylor and Francis Group: Boca Raton, FL, USA, 2005.

104. Halliwell, B.; Gutteridge, J.M.C.; Cross, C.E. Free radicals, antioxidants and human disease: Where are we now? J. Lab. Clin. Med. 1992, 119, 598-620.

105. Kontoghiorghes, G.J. Iron Chelation in Biochemistry and Medicine. In Free Radicals, Oxidant Stress and Drug Action; Rice-Evans, C., Ed.; Rechelieu Press: London, UK, 1987; pp. 277-303.

106. Kontoghiorghes, G.J.; Kontoghiorghe, C.N. Prospects for the introduction of targeted antioxidant drugs for the prevention and treatment of diseases related to free radical pathology. Expert Opin. Investig. Drugs 2019, 28, 593-603. [CrossRef]

107. Perron, N.R.; Brumaghim, J.L. A review of the antioxidant mechanisms of polyphenol compounds related to iron binding. Cell Biochem. Biophys. 2009, 53, 75-100. [CrossRef]

108. Korkina, L.G.; Afanas'ev, I.B. Antioxidant and chelating properties of flavonoids. Adv. Pharmacol. 1997, 38, 151-163. 
109. Nkhili, E.; Loonis, M.; Mihai, S.; El Hajji, H.; Dangles, O. Reactivity of food phenols with iron and copper ions: Binding, dioxygen activation and oxidation mechanisms. Food Funct. 2014, 5, 1186-1220. [CrossRef] [PubMed]

110. Kontoghiorghes, G.J.; Jackson, M.I.; Lunec, J. In vitro screening of iron chelators using models of free radical damage. Free Rad. Res. Commun. 1986, 2, 115-124. [CrossRef]

111. Hong, Y.L.; Pan, H.Z.; Scott, M.D.; Meshnick, S.R. Activated oxygen generation by a primaquine metabolite: Inhibition by antioxidants derived from Chinese herbal remedies. Free Radic. Biol. Med. 1992, 12, 213-218. [CrossRef] [PubMed]

112. Lee, K.G.; Shibamoto, T. Antioxidant properties of aroma compounds isolated from soybeans and mung beans. J. Agric. Food Chem. 2000, 48, 4290-4293. [CrossRef] [PubMed]

113. Wei, A.; Mura, K.; Shibamoto, T. Antioxidative activity of volatile chemicals extracted from beer. J. Agric. Food Chem. 2001, 49, 4097-4101. [CrossRef] [PubMed]

114. Kang, K.S.; Kim, H.Y.; Baek, S.H.; Yoo, H.H.; Park, J.H.; Yokozawa, T. Study on the hydroxyl radical scavenging activity changes of ginseng and ginsenoside-Rb2 by heat processing. Biol. Pharm. Bull. 2007, 30, 724-728. [CrossRef] [PubMed]

115. Wang, H.; Jenner, A.M.; Lee, C.Y.J.; Shui, G.; Tang, S.Y.; Whiteman, M.; Wenk, M.R.; Halliwell, B. The identification of antioxidants in dark soy sauce. Free Radic. Res. 2007, 41, 479-488. [CrossRef] [PubMed]

116. Kang, K.S.; Yamabe, N.; Kim, H.Y.; Yokozawa, T. Role of maltol in advanced glycation end products and free radicals: In-vitro and in-vivo studies. J. Pharm. Pharmacol. 2008, 60, 445-452. [CrossRef] [PubMed]

117. Minaiyan, M.; Mostaghel, E.; Mahzouni, P. Preventive Therapy of Experimental Colitis with Selected iron Chelators and Anti-oxidants. Int. J. Prev. Med. 2012, 3 (Suppl. S1), S162-S169, PMCID:PMC3399289. [PubMed]

118. Han, Y.; Xu, Q.; Hu, J.N.; Han, X.Y.; Li, W.; Zhao, L.C. Maltol, a food flavoring agent, attenuates acute alcohol-induced oxidative damage in mice. Nutrients 2015, 7, 682-696, PMCID:PMC4303861. [CrossRef] [PubMed]

119. Anwar-Mohamed, A.; El-Kadi, A.O. Induction of cytochrome P450 1a1 by the food flavoring agent, maltol. Toxicol. In Vitro 2007, 21, 685-690. [CrossRef] [PubMed]

120. Liu, W.; Wang, Z.; Hou, J.G.; Zhou, Y.D.; He, Y.F.; Jiang, S.; Wang, Y.P.; Ren, S.; Li, W. The Liver Protection Effects of Maltol, a Flavoring Agent, on Carbon Tetrachloride-Induced Acute Liver Injury in Mice via Inhibiting Apoptosis and Inflammatory Response. Molecules 2018, 23, 2120, PMCID:PMC6225187. [CrossRef] [PubMed]

121. Guo, N.; Li, C.; Liu, Q.; Liu, S.; Huan, Y.; Wang, X.; Bai, G.; Yang, M.; Sun, S.; Xu, C.; et al. Maltol, a food flavor enhancer, attenuates diabetic peripheral neuropathy in streptozotocin-induced diabetic rats. Food Funct. 2018, 9, 6287-6297. [CrossRef] [PubMed]

122. Wang, Z.; Hao, W.; Hu, J.; Mi, X.; Han, Y.; Ren, S.; Jiang, S.; Wang, Y.; Li, X.; Li, W. Maltol Improves APAP-Induced Hepatotoxicity by Inhibiting Oxidative Stress and Inflammation Response via NF-kB and PI3K/Akt Signal Pathways. Antioxidants 2019, 8, 395, PMCID:PMC6769439. [CrossRef] [PubMed]

123. Singh, R.K.; Barrand, M.A. Lipid peroxidation effects of a novel iron compound, ferric maltol. A comparison with ferrous sulphate. J. Pharm. Pharmacol. 1990, 42, 276-279. [CrossRef] [PubMed]

124. Kontoghiorghes, G.J. Structure/red blood cell permeability activity of iron (III) chelator complexes. Inorg. Chim. Acta 1988, 151, 101-106. [CrossRef]

125. Kontoghiorghes, G.J.; Sheppard, L. Simple synthesis of the potent iron chelators 1-alkyl-3-hydroxy-2-methylpyrid-4-ones. Inorg. Chim. Acta Bioinorg. Chem. 1987, 136, L11-L12. [CrossRef]

126. Kontoghiorghes, G.J.; May, A. Uptake and intracellular distribution of iron from transferrin and chelators in erythroid cells. Biol. Met. 1990, 3, 183-187. [CrossRef]

127. Forsbeck, K.; Nilsson, K.; Kontoghiorghes, G.J. Variation in iron accumulation, transferrin membrane binding and DNA synthesis in the K-562 and U-937 cell lines induced by chelators and their iron complexes. Eur. J. Haematol. 1987, 39, 318-325. [CrossRef]

128. Kontoghiorghes, G.J.; Piga, A.; Hoffbrand, A.V. Cytotoxic and DNA-inhibitory effects of iron chelators on human leukaemic cell lines. Hematol. Oncol. 1986, 4, 195-204. [CrossRef]

129. Neilands, J.B. Siderophores: Structure and function of microbial iron transport compounds. J. Biol. Chem. 1995, 270, 26723-26726. [CrossRef]

130. Weinberg, E.D. Iron depletion: A defense against intracellular infection and neoplasm. Life Sci. 1992, 50, 1289-1297. [CrossRef]

131. Andrews, S.C.; Robinson, A.K.; Rodríguez-Quiñones, F. Bacterial iron homeostasis. FEMS Microbiol. Rev. $2003,27,215-237$. [CrossRef]

132. Kontoghiorghes, G.J.; Weinberg, E.D. Iron: Mammalian defense systems, mechanisms of disease, and chelation therapy approaches. Blood Rev. 1995, 9, 33-45. [CrossRef]

133. Kontoghiorghes, G.J.; Kolnagou, A.; Skiada, A.; Petrikkos, G. The role of iron and chelators on infections in iron overload and non iron loaded conditions: Prospects for the design of new antimicrobial therapies. Hemoglobin 2010, 34, 227-239. [CrossRef]

134. Robins-Browne, R.M.; Pipic, J.K. Desferrioxamine and systemic yersiniosis. Lancet 1983, II, 1372. [CrossRef]

135. Boelaert, J.R.; Fenves, A.Z.; Coburn, J.W. Deferoxamine therapy and mucormycosis in dialysis patients: Report of an international registry. Am. J. Kidney Dis. 1991, 18, 660-667. [CrossRef]

136. Wilson, B.R.; Bogdan, A.R.; Miyazawa, M.; Hashimoto, K.; Tsuji, Y. Siderophores in Iron Metabolism: From Mechanism to Therapy Potential. Trends Mol. Med. 2016, 22, 1077-1090. [CrossRef] [PubMed]

137. Page, M.G.P. The Role of Iron and Siderophores in Infection, and the Development of Siderophore Antibiotics. Clin. Infect. Dis. 2019, 69 (Suppl. S7), S529-S537. [CrossRef] [PubMed] 
138. Ibrahim, A.S.; Edwards, J.E., Jr.; Fu, Y.; Spellberg, B. Deferiprone iron chelation as a novel therapy for experimental mucormycosis. J. Antimicrob. Chemother. 2006, 58, 1070-1073. [CrossRef] [PubMed]

139. Brock, J.H.; Licéaga, J.; Kontoghiorghes, G.J. The effect of synthetic iron chelators on bacterial growth in human serum. FEMS Microbiol. Immunol. 1988, 1, 55-60. [CrossRef]

140. Heppner, D.G.; Hallaway, P.E.; Kontoghiorghes, G.J.; Eaton, J.W. Antimalarial properties of orally active iron chelators. Blood 1988, 72, 358-361. [CrossRef]

141. Brock, J.H.; Licéaga, J.; Arthur, H.M.; Kontoghiorghes, G.J. Effect of novel 1-alkyl-3-hydroxy-2-methylpyrid-4-one chelators on uptake and release of iron from macrophages. Am. J. Hematol. 1990, 34, 21-25. [CrossRef]

142. Kontoghiorghes, G.J.; Kleanthous, M.; Kontoghiorghe, C.N. The History of Deferiprone (L1) and the Paradigm of the Complete Treatment of Iron Overload in Thalassaemia. Mediterr. J. Hematol. Infect. Dis. 2020, 12, e2020011. [CrossRef]

143. Kontoghiorghes, G.J. Oral iron chelation is here. Br. Med. J. 1991, 303, 1279-1280. [CrossRef]

144. Kontoghiorghes, G.J. Chelators affecting iron absorption in mice. Drug Res. 1990, 40, 1332-1335.

145. Barrand, M.A.; Callingham, B.A.; Hider, R.C. Effects of the pyrones, maltol and ethyl maltol, on iron absorption from the rat small intestine. J. Pharm. Pharmacol. 1987, 39, 203-211. [CrossRef]

146. Barrand, M.A.; Callingham, B.A.; Dobbin, P.; Hider, R.C. Dissociation of a ferric maltol complex and its subsequent metabolism during absorption across the small intestine of the rat. Br. J. Pharmacol. 1991, 102, 723-729, PMCID:PMC1917947. [CrossRef] [PubMed]

147. Yamamoto, R.S.; Williams, G.M.; Frangel, H.H.; Weisburger, J.H. 8-hydroxyquinoline: Chronic toxicity and inhibitory effect on the carcinogenicity of N-2- fluorenylacetamide. Toxicol. Appl. Pharmacol. 1971, 19, 687-698. [CrossRef]

148. Williams, G.M.; Yamamoto, R.S. Absence of stainable iron from preneoplastic and neoplastic lesions in rat liver with 8hydroxyquinoline-induced siderosis. J. Natl. Cancer Inst. 1972, 49, 685-692. [PubMed]

149. Hershko, C.; Konijn, A.M.; Nick, H.P.; Breuer, W.; Cabantchik, Z.I.; Link, G. ICL670A: A new synthetic oral chelator: Evaluation in hypertransfused rats with selective radioiron probes of hepatocellular and reticuloendothelial iron stores and in iron-loaded rat heart cells in culture. Blood 2001, 97, 1115-1122. [CrossRef] [PubMed]

150. Eghbali, A.; Shokri, P.; Afzal, R.R.; Bagheri, B. A 1-year randomized trial of deferasirox alone versus deferasirox and deferoxamine combination for the treatment of iron overload in thalassemia major. Transfus. Apher. Sci. 2019, 58, 429-433. [CrossRef]

151. Karimi, M.; Haghpanah, S.; Bahoush, G.; Ansari, S.; Azarkeivan, A.; Shahsavani, A.; Bazrafshan, A.; Jangjou, A. Evaluation of Efficacy, Safety, and Satisfaction Taking Deferasirox Twice Daily Versus Once Daily in Patients With Transfusion-Dependent Thalassemia. J. Pediatr. Hematol. Oncol. 2020, 42, 23-26. [CrossRef]

152. Pepe, A.; Meloni, A.; Pistoia, L.; Cuccia, L.; Gamberini, M.R.; Lisi, R.; D’Ascola, D.G.; Rosso, R.; Allò, M.; Spasiano, A.; et al. MRI multicentre prospective survey in thalassaemia major patients treated with deferasirox versus deferiprone and desferrioxamine. Br. J. Haematol. 2018, 183, 783-795. [CrossRef]

153. Kolnagou, A.; Kleanthous, M.; Kontoghiorghes, G.J. Reduction of body iron stores to normal range levels in thalassaemia by using a deferiprone/deferoxamine combination and their maintenance thereafter by deferiprone monotherapy. Eur. J. Haematol. 2010, 85, 430-438. [CrossRef]

154. Kolnagou, A.; Kontoghiorghe, C.N.; Kontoghiorghes, G.J. Prevention of Iron Overload and Long Term Maintenance of Normal Iron Stores in Thalassaemia Major Patients using Deferiprone or Deferiprone Deferoxamine Combination. Drug Res. 2017, 67, 404-411. [CrossRef]

155. Lin, C.H.; Chen, X.; Wu, C.C.; Wu, K.H.; Song, T.S.; Weng, T.F.; Hsieh, Y.W.; Peng, C.T. Therapeutic mechanism of combined oral chelation therapy to maximize efficacy of iron removal in transfusion-dependent thalassemia major-A pilot study. Expert Rev. Hematol. 2019, 12, 265-272. [CrossRef]

156. Boddaert, N.; Le Quan Sang, K.H.; Rötig, A.; Leroy-Willig, A.; Gallet, S.; Brunelle, F.; Sidi, D.; Thalabard, J.C.; Munnich, A.; Cabantchik, Z.I. Selective iron chelation in Friedreich ataxia: Biologic and clinical implications. Blood 2007, 110, 401-408. [CrossRef] [PubMed]

157. Martin-Bastida, A.; Ward, R.J.; Newbould, R.; Piccini, P.; Sharp, D.; Kabba, C.; Patel, M.C.; Spino, M.; Connelly, J.; Tricta, F.; et al. Brain iron chelation by deferiprone in a phase 2 randomised double-blinded placebo controlled clinical trial in Parkinson's disease. Sci. Rep. 2017, 7, 1398. [CrossRef] [PubMed]

158. Zorzi, G.; Zibordi, F.; Chiapparini, L.; Bertini, E.; Russo, L.; Piga, A.; Longo, F.; Garavaglia, B.; Aquino, D.; Savoiardo, M.; et al. Iron-related MRI images in patients with pantothenate kinase-associated neurodegeneration (PKAN) treated with deferiprone: Results of a phase II pilot trial. Mov. Disord. 2011, 26, 1756-1759. [CrossRef] [PubMed]

159. Forni, G.L.; Balocco, M.; Cremonesi, L.; Abbruzzese, G.; Parodi, R.C.; Marchese, R. Regression of symptoms after selective iron chelation therapy in a case of neurodegeneration with brain iron accumulation. Mov. Disord. 2008, 23, 904-907. [CrossRef]

160. Kolnagou, A.; Kleanthous, M.; Kontoghiorghes, G.J. Efficacy, compliance and toxicity factors are affecting the rate of normalization of body iron stores in thalassemia patients using the deferiprone and deferoxamine combination therapy. Hemoglobin 2011, 35, 186-198. [CrossRef] [PubMed]

161. Petry, N.; Egli, I.; Zeder, C.; Walczy, K.T.; Hurrell, R. Polyphenols and phytic acid contribute to the low iron bioavailability from common beans in young women. J. Nutr. 2010, 140, 1977-1982. [CrossRef]

162. Sotelo, A.; González-Osnaya, L.; Sánchez-Chinchillas, A.; Trejo, A. Role of oxate, phytate, tannins and cooking on iron bioavailability from foods commonly consumed in Mexico. Int. J. Food Sci. Nutr. 2010, 61, 29-39. [CrossRef] 
163. Campbell, N.R.; Hasinoff, B.B. Iron supplements: A common cause of drug interactions. Br. J. Clin. Pharmacol. 1991, 31, 251-255. [CrossRef]

164. Jaramillo, Á.; Briones, L.; Andrews, M.; Arredondo, M.; Olivares, M.; Brito, A.; Pizarro, F. Effect of phytic acid, tannic acid and pectin on fasting iron bioavailability both in the presence and absence of calcium. J. Trace Elem. Med. Biol. 2015, 30, 112-117. [CrossRef]

165. Kojima, Y.; Yoshikawa, Y.; Ueda, E.; Kondo, M.; Takahashi, S.; Matsukura, T.; Sakurai, H.; Hiroi, T.; Imaoka, S.; Funae, Y. Blood glucose lowering and toxicological effects of zinc (II) complexes with maltol, threonine, and picolinic acid. Res. Commun. Mol. Pathol. Pharmacol. 2002, 112, 91-104. [PubMed]

166. Wang, H.; Shao, B.; Yu, H.; Xu, F.; Wang, P.; Yu, K.; Han, Y.; Song, M.; Li, Y.; Cao, Z. Neuroprotective role of hyperforin on aluminum maltolate-induced oxidative damage and apoptosis in PC12 cells and SH-SY5Y cells. Chem. Biol. Interact. 2019, 299, 15-26. [CrossRef] [PubMed]

167. Ott, D.B.; Hartwig, A.; Stillman, M.J. Competition between $\mathrm{Al}^{3+}$ and $\mathrm{Fe}^{3+}$ binding to human transferrin and toxicological implications: Structural investigations using ultra-high resolution ESI MS and CD spectroscopy. Metallomics 2019, 11,968-981. [CrossRef]

168. Kontoghiorghes, G.J.; Barr, J.; Baillod, R.A. Studies of aluminium mobilisation in renal dialysis patients using the oral chelator 1, 2-dimethyl-3-hydroxypyrid-4-one. Arzn Forsch Drug Res. 1994, 44, 522-526.

169. Pergola, P.E.; Fishbane, S.; Ganz, T. Novel Oral Iron Therapies for Iron Deficiency Anemia in Chronic Kidney Disease Adv. Chronic. Kidney Dis. 2019, 26, 272-291. [CrossRef] [PubMed]

170. Murawska, N.; Fabisiak, A.; Fichna, J. Anemia of Chronic Disease and Iron Deficiency Anemia in Inflammatory Bowel Diseases: Pathophysiology, Diagnosis, and Treatment. Inflamm. Bowel Dis. 2016, 22, 1198-1208. [CrossRef] [PubMed]

171. Khoury, A.; Pagan, K.A.; Farland, M.Z. Ferric Maltol: A New Oral Iron Formulation for the Treatment of Iron Deficiency in Adults. Ann. Pharmacother. 2021, 55, 222-229. [CrossRef] [PubMed]

172. Stallmach, A.; Büning, C. Ferric maltol (ST10): A novel oral iron supplement for the treatment of iron deficiency anemia in inflammatory bowel disease. Expert Opin. Pharmacother. 2015, 16, 2859-2867. [CrossRef] [PubMed]

173. Bokemeyer, B.; Krummenerl, A.; Maaser, C.; Howaldt, S.; Mroß, M.; Mallard, N. Randomized Open-Label Phase 1 Study of the Pharmacokinetics of Ferric Maltol in Inflammatory Bowel Disease Patients with Iron Deficiency. Eur. J. Drug Metab. Pharmacokinet. 2017, 42, 229-238. [CrossRef] [PubMed]

174. Harvey, R.S.; Reffitt, D.M.; Doig, L.A.; Meenan, J.; Ellis, R.D.; Thompson, R.P.; Powell, J.J. Ferric trimaltol corrects iron deficiency anaemia in patients intolerant of iron. Aliment Pharmacol. Ther. 1998, 12, 845-848. [CrossRef]

175. Kelsey, S.M.; Hider, R.; Bloor, J.R.C.; Blake, D.R.; Gutteridge, C.N.; Newland, A.C. Absorption of low and therapeutic doses of ferric maltol, a novel ferric iron compound, in iron deficient subjects using a single dose iron absorption test. J. Clin. Pharm. Ther. 1991, 16, 117-122. [CrossRef] [PubMed]

176. Gasche, C.; Ahmad, T.; Tulassay, Z.; Baumgart, D.C.; Bokemeyer, B.; Büning, C.; Howaldt, S.; Stallmach, A.; AEGIS Study Group Ferric maltol is effective in correcting iron deficiency anemia in patients with inflammatory bowel disease: Results from a phase-3 clinical trial program. Inflamm. Bowel Dis. 2015, 21, 579-588. [CrossRef] [PubMed]

177. Reffitt, D.M.; Burden, T.J.; Seed, P.T.; Wood, J.; Thompson, R.P.; Powell, J.J. Assessment of iron absorption from ferric trimaltol. Ann. Clin. Biochem. 2000, 37, 457-466. [CrossRef] [PubMed]

178. Schmidt, C.; Ahmad, T.; Tulassay, Z.; Baumgart, D.C.; Bokemeyer, B.; Howaldt, S.; Stallmach, A.; Büning, C.; The AEGIS Study Group. Ferric maltol therapy for iron deficiency anaemia in patients with inflammatory bowel disease: Long-term extension data from a Phase 3 study. Aliment. Pharmacol Ther. 2016, 44, 259-270, PMCID:PMC5089582. [CrossRef] [PubMed]

179. Olsson, K.M.; Fuge, J.; Brod, T.; Kamp, J.C.; Schmitto, J.; Kempf, T.; Bauersachs, J.; Hoeper, M.M. Oral iron supplementation with ferric maltol in patients with pulmonary hypertension. Eur. Respir. J. 2020, 56, 2000616, PMCID:PMC7676873. [CrossRef] [PubMed]

180. Kopyt, N.P.; AEGIS-CKD Study Group. Efficacy and safety of oral ferric maltol (FM) in treating iron-deficiency anemia (IDA) in patients with CKD: Randomized controlled trial [FR-OR120]. J. Am. Soc. Nephrol. 2018, 29, 70-71.

181. Punj, S.; Ghafourian, K.; Ardehali, H. Iron deficiency and supplementation in heart failure and chronic kidney disease. Mol. Aspects Med. 2020, 75, 100873, PMCID:PMC7554149. [CrossRef] [PubMed]

182. Nataatmadja, M.S.; Francis, R. Recurrent severe hypophosphatemia following intravenous iron administration. Clin. Case Rep. 2020, 8, 243-246, PMCID:PMC7044372. [CrossRef] [PubMed]

183. Kshirsagar, A.V.; Li, X. Long-Term Risks of Intravenous Iron in End-Stage Renal Disease Patients. Adv. Chronic Kidney Dis. 2019, 26, 292-297. [CrossRef] [PubMed]

184. Liabeuf, S.; Gras, V.; Moragny, J.; Laroche, M.L.; Andrejak, M.; French National Network of Pharmacovigilance Centers. Ulceration of the oral mucosa following direct contact with ferrous sulfate in elderly patients: A case report and a review of the French National Pharmacovigilance Database. Clin. Interv. Aging. 2014, 9, 737-740, PMCID:PMC4008291. [CrossRef] [PubMed]

185. Ferrari, P.; Nicolini, A.; Manca, M.L.; Rossi, G.; Anselmi, L.; Conte, M.; Carpi, A.; Bonino, F. Treatment of mild non-chemotherapyinduced iron deficiency anemia in cancer patients: Comparison between oral ferrous bisglycinate chelate and ferrous sulfate. Biomed. Pharmacother. 2012, 66, 414-418. [CrossRef] [PubMed] 
186. Schümann, K.; Kroll, S.; Weiss, G.; Frank, J.; Biesalski, H.K.; Daniel, H.; Friel, J.; Solomons, N.W. Monitoring of hematological, inflammatory and oxidative reactions to acute oral iron exposure in human volunteers: Preliminary screening for selection of potentially-responsive biomarkers. Toxicology 2005, 212, 10-23. [CrossRef] [PubMed]

187. Thompson, K.H.; Barta, C.A.; Orvig, C. Metal complexes of maltol and close analogues in medicinal inorganic chemistry. Chem. Soc. Rev. 2006, 35, 545-556. [CrossRef] [PubMed]

188. Kontoghiorghes, G.J.; Efstathiou, A.; Ioannou-Loucaides, S.; Kolnagou, A. Chelators controlling metal metabolism and toxicity pathways: Applications in cancer prevention, diagnosis and treatment. Hemoglobin 2008, 32, 217-227. [CrossRef]

189. Barve, A.; Kumbhar, A.; Bhat, M.; Joshi, B.; Butcher, R.; Sonawane, U.; Joshi, R. Mixed-ligand copper(II) maltolate complexes: Synthesis, characterization, DNA binding and cleavage, and cytotoxicity. Inorg. Chem. 2009, 48, 9120-9132. [CrossRef] [PubMed]

190. Chukwuma, C.I.; Mashele, S.S.; Eze, K.C.; Matowane, G.R.; Islam, S.M.; Bonnet, S.L.; Noreljaleel, A.E.M.; Ramorobi, L.M. A comprehensive review on zinc(II) complexes as anti-diabetic agents: The advances, scientific gaps and prospects. Pharmacol. Res. 2020, 155, 104744. [CrossRef] [PubMed]

191. Kostrzewa, A.; Páli, T.; Froncisz, W.; Marsh, D. Membrane location of spin-labeled cytochrome c determined by paramagnetic relaxation agents. Biochemistry 2000, 39, 6066-6074. [CrossRef] [PubMed]

192. Kandioller, W.; Hartinger, C.G.; Nazarov, A.A.; Bartel, C.; Skocic, M.; Jakupec, M.A.; Arion, V.B.; Keppler, B.K. Maltol-derived ruthenium-cymene complexes with tumor inhibiting properties: The impact of ligand-metal bond stability on anticancer activity in vitro. Chemistry 2009, 15, 12283-12291. [CrossRef] [PubMed]

193. Mehtab, S.; Gonçalves, G.; Roy, S.; Tomaz, A.I.; Santos-Silva, T.; Santos, M.F.A.; Romão, M.J.; Jakusch, T.; Kiss, T.; Pessoa, J.C. Interaction of vanadium(IV) with human serum apo-transferrin. J. Inorg. Biochem. 2013, 121, 187-195. [CrossRef] [PubMed]

194. Satoh, E.; Yasuda, I.; Yamada, T.; Suzuki, Y.; Ohyashiki, T. Involvement of NO generation in aluminum-induced cell death. Biol. Pharm. Bull. 2007, 30, 1390-1394. [CrossRef] [PubMed]

195. Yasumoto, E.; Nakano, K.; Nakayachi, T.; Morshed, S.R.M.; Hashimoto, K.; Kikuchi, H.; Nishikawa, H.; Kawase, M.; Sakagami, H. Cytotoxic activity of deferiprone, maltol and related hydroxyketones against human tumor cell lines. Anticancer. Res. 2004, 24, 755-762. [PubMed]

196. Chitambar, C.R. The therapeutic potential of iron-targeting gallium compounds in human disease: From basic research to clinical application. Pharmacol. Res. 2017, 115, 56-64. [CrossRef] [PubMed]

197. Pan, B.; Li, Y.; Zhang, J.; Zhou, Y.; Li, L.; Xue, X.; Li, H.; Niu, Q. Role of mGluR 1 in synaptic plasticity impairment induced by maltol aluminium in rats. Environ. Toxicol. Pharmacol. 2020, 78, 103406. [CrossRef] [PubMed]

198. Enyedy, É.A.; Dömötör, O.; Bali, K.; Hetényi, A.; Tuccinardi, T.; Keppler, B.K. Interaction of the anticancer gallium(III) complexes of 8-hydroxyquinoline and maltol with human serum proteins. J. Biol. Inorg. Chem. 2015, 20, 77-88. [CrossRef] [PubMed]

199. Wu, X.; Wang, T.W.; Lessmann, G.M.; Saleh, J.; Liu, X.; Chitambar, C.R.; Hwang, S.T. Gallium maltolate inhibits human cutaneous T-cell lymphoma tumor development in mice. J. Investig. Dermatol. 2015, 135, 877-884. [CrossRef] [PubMed]

200. Chitambar, C.R.; Al-Gizawiy, M.M.; Alhajala, H.S.; Pechman, K.R.; Wereley, J.P.; Wujek, R.; Clark, P.A.; Kuo, J.S.; Antholine, W.E.; Schmainda, K.M. Gallium Maltolate Disrupts Tumor Iron Metabolism and Retards the Growth of Glioblastoma by Inhibiting Mitochondrial Function and Ribonucleotide Reductase. Mol. Cancer Ther. 2018, 17, 1240-1250, PMCID:PMC5984712. [CrossRef] [PubMed]

201. Merli, D.; Profumo, A.; Bloise, N.; Risi, G.; Momentè, S.; Cucca, L.; Visai, L. Indium/Gallium Maltolate Effects on Human Breast Carcinoma Cells: In Vitro Investigation on Cytotoxicity and Synergism with Mitoxantrone. ACS Omega 2018, 3, 4631-4640, PMCID:PMC6044947. [CrossRef] [PubMed]

202. Bernstein, L.R.; van der Hoeven, J.J.; Boer, R.O. Hepatocellular carcinoma detection by gallium scan and subsequent treatment by gallium maltolate: Rationale and case study. Anticancer Agents Med. Chem. 2011, 11, 585-590. [CrossRef] [PubMed]

203. Arnold, C.E.; Bordin, A.; Lawhon, S.D.; Libal, M.C.; Bernstein, L.R.; Cohen, N.D. Antimicrobial activity of gallium maltolate against Staphylococcus aureus and methicillin-resistant S. aureus and Staphylococcus pseudintermedius: An in vitro study. Vet. Microbiol. 2012, 155, 389-394. [CrossRef] [PubMed]

204. Fecteau, M.E.; Aceto, H.W.; Bernstein, L.R.; Sweeney, R.W. Comparison of the antimicrobial activities of gallium nitrate and gallium maltolate against Mycobacterium avium subsp. paratuberculosis in vitro. Vet. J. 2014, 202, 195-197. [CrossRef] [PubMed]

205. Hijazi, S.; Visaggio, D.; Pirolo, M.; Frangipani, E.; Bernstein, L.; Visca, P. Antimicrobial Activity of Gallium Compounds on ESKAPE Pathogens. Front. Cell Infect. Microbiol. 2018, 8, 316, PMCID:PMC6139391. [CrossRef] [PubMed]

206. Ball, K.R.; Sampieri, F.; Chirino, M.; Hamilton, D.L.; Blyth, R.I.; Sham, T.K.; Dowling, P.M.; Thompson, J. Synchrotron X-ray fluorescence microscopy of gallium in bladder tissue following gallium maltolate administration during urinary tract infection. Antimicrob Agents Chemother. 2013, 57, 5197-5201, PMCID:PMC3811287. [CrossRef] [PubMed]

207. Monk, C.S.; Sweeney, R.W.; Bernstein, L.R.; Fecteau, M.E. Serum and tissue concentrations of gallium after oral administration of gallium nitrate and gallium maltolate to neonatal calves. Am. J. Vet. Res. 2016, 77, 151-155. [CrossRef] [PubMed]

208. Sampieri, F.; Alcorn, J.; Allen, A.L.; Clark, C.R.; Vannucci, F.A.; Pusterla, N.; Mapes, S.; Ball, K.R.; Dowling, P.M.; Thompson, J.; et al. Pharmacokinetics of gallium maltolate in Lawsonia intracellularis-infected and uninfected rabbits. J. Vet. Pharmacol. Ther. 2014, 37, 486-499. [CrossRef] [PubMed]

209. Pollina, G.F.; Pepe, M.; Dean, A.; Di Marco, V.; Marton, D. Reduction in absorption of gallium maltolate in adult horses following oral administration with food: Chemistry and pharmacokinetics. J. Vet. Pharmacol. Ther. 2013, 36, 456-461. [CrossRef] [PubMed] 
210. Martens, R.J.; Mealey, K.; Cohen, N.D.; Harrington, J.R.; Chaffin, M.K.; Taylor, R.J.; Bernstein, L.R. Pharmacokinetics of gallium maltolate after intragastric administration in neonatal foals. Am. J. Vet. Res. 2007, 68, 1041-1044. [CrossRef] [PubMed]

211. Richardson, D.R. Molecular mechanisms of iron uptake by cells and the use of iron chelators for the treatment of cancer. Curr. Med. Chem. 2005, 12, 2711-2729. [CrossRef] [PubMed]

212. Markowicz-Piasecka, M.; Skupień, A.; Mikiciuk-Olasik, E.; Sikora, J. Biocompatibility Studies of Gadolinium Complexes with Iminodiacetic Acid Derivatives. Biol. Trace Elem. Res. 2019, 189, 426-436. [CrossRef]

213. Parghane, R.V.; Basu, S. Bilateral Orbital Soft-Tissue Metastases from Renal Neuroendocrine Tumor: Successful Theranostic Application of 68Ga/177Lu-DOTATATE with Improvement of Vision. J. Nucl. Med. Technol. 2019, 47, 171-172. [CrossRef]

214. Rund, D. Intravenous iron: Do we adequately understand the short- and long-term risks in clinical practice? Br. J. Haematol. 2020. [CrossRef]

215. Auerbach, M.; Gafter-Gvili, A.; Macdougall, I.C. Intravenous iron: A framework for changing the management of iron deficiency. Lancet Haematol. 2020, 7, e342-e350. [CrossRef] [PubMed]

216. Manz, D.H.; Blanchette, N.L.; Paul, B.T.; Torti, F.M.; Torti, S.V. Iron and cancer: Recent insights. Ann. N. Y. Acad. Sci. 2016, 1368, 149-161. [CrossRef] [PubMed]

217. Voest, E.E.; Vreugdenhil, G.; Marx, J.J.M. Iron-chelating agents in non-iron overload conditions. Ann. Intern. Med. 1994, 120, 490-499. [CrossRef] [PubMed]

218. Fernandes, K.E.; Weeks, K.; Carter, D.A. Lactoferrin Is Broadly Active against Yeasts and Highly Synergistic with Amphotericin B. Antimicrob Agents Chemother. 2020, 64, e02284-19. [CrossRef]

219. Rosa, L.; Cutone, A.; Lepanto, M.S.; Paesano, R.; Valenti, P. Lactoferrin: A Natural Glycoprotein Involved in Iron and Inflammatory Homeostasis. Int. J. Mol. Sci. 2017, 18, 1985. [CrossRef]

220. González-Chávez, S.A.; Arévalo-Gallegos, S.; Rascón-Cruz, Q. Lactoferrin: Structure, function and applications. Int. J. Antimicrob. Agents 2009, 33, 301.e1-301.e8. [CrossRef] 